\title{
ALD1 Regulates Basal Immune Components and Early Inducible Defense Responses in Arabidopsis
}

\author{
Nicolás M. Cecchini, ${ }^{1}$ Ho Won Jung, ${ }^{1,2}$ Nancy L. Engle, ${ }^{3}$ Timothy J. Tschaplinski, ${ }^{3}$ and \\ Jean T. Greenberg ${ }^{1}$ \\ ${ }^{1}$ Department of Molecular Genetics and Cell Biology, The University of Chicago, 929 East 57th Street GCIS 524W, Chicago \\ 60637, U.S.A.; ${ }^{2}$ Department of Genetic Engineering, Dong-A University, 37 Nakdong-Daero 550beon-gil, Saha-gu, Busan \\ 604-714, Korea; and ${ }^{3}$ Oak Ridge National Lab, PO Box 2008, Oak Ridge, TN 37831, U.S.A.
}

Submitted 27 June 2014. Accepted 24 October 2014.

\begin{abstract}
Robust immunity requires basal defense machinery to mediate timely responses and feedback cycles to amplify defenses against potentially spreading infections. AGD2-LIKE DEFENSE RESPONSE PROTEIN 1 (ALD1) is needed for the accumulation of the plant defense signal salicylic acid (SA) during the first hours after infection with the pathogen Pseudomonas syringae and is also upregulated by infection and SA. ALD1 is an aminotransferase with multiple substrates and products in vitro. Pipecolic acid (Pip) is an ALD1-dependent bioactive product induced by $P$. syringae. Here, we addressed roles of ALD1 in mediating defense amplification as well as the levels and responses of basal defense machinery. ALD1 needs immune components PAD4 and ICS1 (an SA synthesis enzyme) to confer disease resistance, possibly through a transcriptional amplification loop between them. Furthermore, ALD1 affects basal defense by controlling microbial-associated molecular pattern (MAMP) receptor levels and responsiveness. Vascular exudates from uninfected $A L D 1$-overexpressing plants confer local immunity to the wild type and ald1 mutants yet are not enriched for Pip. We infer that, in addition to affecting Pip accumulation, ALD1 produces non-Pip metabolites that play roles in immunity. Thus, distinct metabolite signals controlled by the same enzyme affect basal and early defenses versus later defense responses, respectively.
\end{abstract}

Plant innate immunity has several mechanisms that enable the recognition of microorganisms through different types of immune receptors. Pattern recognition receptor (PRR) complexes sense conserved microbial or self-derived molecules called pathogen-associated or danger-associated molecular patterns (PAMPs or DAMPs, respectively) (Boller and Felix 2009; Conrath 2011; Jones and Dangl 2006; Macho and Zipfel 2014), while cytoplasmic or plasma membrane plant resistance (R) proteins recognize, directly or indirectly, specific "avirulence" effectors injected into plants from microbes (Dangl and Jones 2001). One of the best-characterized recognition events in plant immunity is the perception of the bacteria flagellum-derived

N. M. Cecchini and H. W. Jung contributed equally to this work.

Corresponding author: J. T. Greenberg;

E-mail: jgreenbe@uchicago.edu

*The $e$-Xtra logo stands for "electronic extra" and indicates that three supplementary figures and one supplementary table are published online.

(c) 2015 The American Phytopathological Society
MAMP peptide flg22 by the PRR FLAGELLIN-SENSITIVE 2 (FLS2) and its coreceptor, BRI1-ASSOCIATED RECEPTOR KINASE 1 (BAK1) (Chinchilla et al. 2007; Gómez-Gómez and Boller 2000; Heese et al. 2007). flg22-FLS2 binding triggers very rapid responses that include calcium influx, NADPH oxidase dependent oxidative burst (ROS), and mitogen-activated protein kinase (MAPK) or calcium-dependent protein kinase activation during the first approximately $10 \mathrm{~min}$ (Boller and Felix 2009). Later responses include callose deposition to strengthen the cell wall against pathogen attack (Boller and Felix 2009; Gómez-Gómez et al. 1999) and transcriptional reprogramming to activate defense-related genes (Zipfel et al. 2004). These responses are collectively called PAMP-triggered immunity (PTI).

A central player necessary for defense induction against many pathogens is the plant hormone salicylic acid (SA) (Robert-Seilaniantz et al. 2007). SA increases after microorganisms' recognition (Mishina and Zeier 2007; Nawrath et al. 2002; Song et al. 2004a; Tsuda et al. 2008) and is needed for the orchestration of downstream resistance responses (Delaney et al. 1994; Nawrath and Métraux 1999). Moreover, SA is also a key factor for systemic defense programs such as the systemic acquired resistance (SAR) (Cao et al. 1994; Mauch-Mani and Métraux 1998; Nawrath and Métraux 1999). SA can potentiate important basal defense responses, such as flg22-triggered oxidative burst and callose deposition or MAPK cascades, induce a large number of defense genes, such as PATHOGENESIS RELATED GENE 1 (PRl), and defense metabolite production (Beckers et al. 2009; Conrath et al. 2006; Kohler et al. 2002; Sato et al. 2010; Vlot et al. 2009; Yi et al. 2014). SA is synthesized through the action of ISOCHORISMATE SYNTHASE 1 enzyme (ICS1/SID2) in chloroplasts, the source organelle of many phytohormones and defense-related metabolites (Fragnière et al. 2011; Padmanabhan and Dinesh-Kumar 2010; Strawn et al. 2007; Wildermuth et al. 2001).

Correlative data indicate that the timely accumulation of SA determines how susceptible to infections plants are. An early defect in SA accumulation (during the first $24 \mathrm{~h}$ after infection) defines the output of the plant-pathogen interaction (Feys et al. 2001; Glazebrook et al. 1996, 1997, 2003; Gupta et al. 2000; Shapiro and Zhang 2001; Zhou et al. 1998). Several Arabidopsis defense component mutants that show early defects in kinetics of SA production also have increased susceptibility to different pathogens (Glazebrook et al. 1997; Lee et al. 2007; Lu et al. 2003; Nawrath and Métraux 1999; Rietz et al. 2011; Song et al. 2004b; Tsuda et al. 2008). These components form part of the so-called type II regulators of SA, affecting accumulation of SA and SA-dependent compounds, but are not directly implicated 
in SA synthesis (Lu et al. 2009). Examples of those regulators include AGD2-LIKE DEFENSE RESPONSE PROTEIN 1 (ALD1), and PHYTOALEXIN DEFICIENT 4 (PAD4) (Jirage et al. 1999; Lu et al. 2003; Song et al. 2004a). Although these regulators are very important for defense induction, how these proteins act to affect the timely production of SA is not known. It is conceivable that they affect early steps after pathogen recognition, before accumulation of SA. They may produce intermediates that maintain basal levels of defense components necessary to respond effectively to pathogens, signals, or signaling intermediates that quickly stimulate SA production.

ALD1 is one particularly interesting example of an SA regulator that is very important for resistance to Pseudomonas syringae strains (Song et al. 2004a). ALDl transcripts are induced within 6 to $12 \mathrm{~h}$ during $P$. syringae infection or by an SA agonist treatment (Song et al. 2004b). ALD1 transcript upregulation depends on another SA regulator, PAD4 (Song et al. 2004a,b). In systemic tissues, during SAR establishment, ALDl transcript induction also depends on the FLAVIN-DEPENDENT MONOOXYGENASE 1 (FMO1), a component necessary for SAR (Návarová et al. 2012). It was suggested that ALD1 participates together with PAD4 and FMO1 in defense signal potentiation to regulate SA-dependent and -independent defenses (Návarová et al. 2012; Song et al. 2004b). In agreement with this idea, aldl mutant plants show diminished SA accumulation, PRI induction, and camalexin production (Song et al. 2004a,b). Interestingly, although these defects in aldl mainly exist at early times and decrease or disappear approximately $24 \mathrm{~h}$ after infection, the mutant plants are more susceptible to $P$. syringae infections.

$A L D 1$ encodes an aminotransferase with multiple substrates and products in vitro (Song et al. 2004a). One proposed ALD1dependent product is pipecolic acid (Pip), a nonprotein amino acid (Návarová et al. 2012). Pip increases in petiole exudates after infection and its accumulation is dependent on ALD1. When applied to the plants, Pip has only a small effect $(<40 \%$ increase) on basal SA in the absence of pathogen infection. However, Pip treatment significantly primes pathogen-induced SA accumulation, similar to the effect of azelaic acid (AZA), another plantproduced priming agent (Jung et al. 2009). Because of ALD1's multiple substrates (Song et al. 2004a) and the dynamic regulation of the $A L D 1$ gene, it is probable that ALD1 produces different
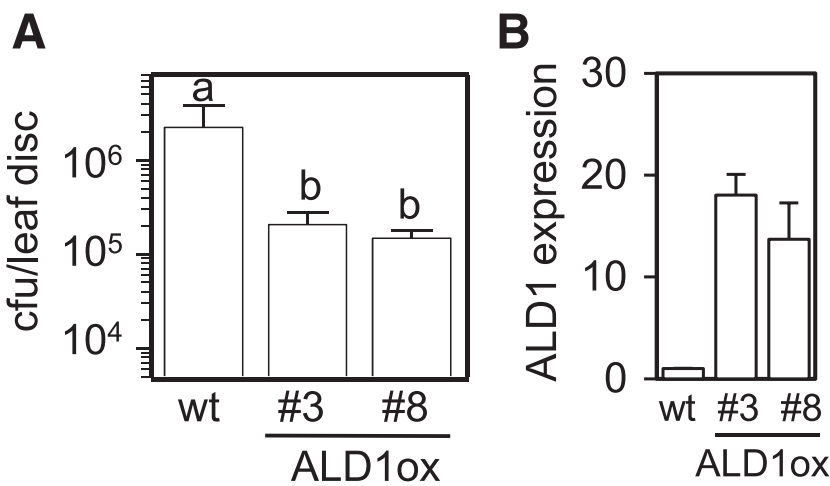

Fig. 1. A, Constitutive expression of $A L D 1$ resulted in reduced growth of a virulent strain of Pseudomonas syringae pv. maculicola ES4326 carrying an empty vector $\left(\right.$ PmaDG3) $\left(\mathrm{OD}_{600}=0.0001\right)$ in transgenic Arabidopsis (ALD1ox) compared with wild-type (wt) Col-0. Two independent transgenic lines (lines 3 and 8 ) were used for syringe inoculations with PmaDG3. Results are means with standard error $(n=6)$. Different letters indicate statistically significant differences $(P<0.01$, analysis of variance, Tukey test). This experiment was repeated three times with similar results. B, ALD1 expression in leaves of wt and ALD1ox transgenic plants (lines 3 and 8 ) were tested by quantitative real-time reverse-transcriptase polymerase chain reaction without any treatments. Error bars indicate standard deviation from three technical replicates. biologically active products that may vary depending on the in vivo conditions. ALD1-dependent metabolites in noninfection conditions (basal state products or metabolites) could differ from those during induction of defenses after infection (defense induced products or metabolites). The identity of those metabolites and their targets are of main importance to understand the key ALD1-dependent early regulation of defenses induction.

Here, we further investigated the effect of ALD1 on early defense responses, other defense regulatory factors, and SA accumulation. Based on studying plants that overexpress ALD1 and ald 1 mutants, we show several roles for ALD1 in regulating (i) basal defense component levels, (ii) a rapid response (in minutes) to flg22, and (iii) slower responses (hours) to pathogen infection, including the transcription of other defense regulators and SA accumulation. A number of effects of ALD1 appear to be independent of Pip accumulation, suggesting the possibility that ALD1 makes or regulates other metabolites with defense-regulatory effects.

\section{RESULTS}

\section{ALD1 overexpression is sufficient} to confer disease resistance.

Plants lacking ALD1 are more susceptible to $P$. syringae (Song et al. 2004a,b). To test whether ALD1 overexpression is sufficient to confer disease resistance, we produced Arabidopsis with constitutively high expression of $A L D 1$ under the control of the Cauliflower mosaic virus (CaMV) 35S promoter. Independent transgenic plant lines (ALD1ox, number 3 and number 8) strongly expressed $A L D 1$ mRNA compared with wild-type (WT) Col-0 plants in pathogen-free conditions (Fig. 1B). To assess the infection phenotype of these lines, we infiltrated leaves with a virulent bacteria and analyzed pathogen growth 3 days after inoculation. ALD1ox plants were overtly indistinguishable from control (not shown) but were more resistant than the WT to virulent $P$. syringae pv. maculicola (PmaDG3) (Fig. 1A). The results support the view that ALD1 is important in determining the level of resistance to $P$. syringae.

\section{ALD1 modulates MAMP-triggered immunity.}

Previously, signaling responses regulated by ALD1 have been characterized as occurring in the order of hours (usually six or more) to days after infection (Song et al. 2004a,b). Moreover, $A L D 1$ transcript levels are upregulated within 6 to $12 \mathrm{~h}$ during virulent $P$. syringae infection. However, an open question is whether a basal state or infection-induced ALD1-dependent products are involved in regulating other defenses. We sought to test a response on a short time scale to determine whether preexisting ALD1 products might have defense-regulatory roles. To do this, we used plants with different ALD1 levels (ald1-T2, WT, and ALD1ox). We monitored a very rapid defense response to the PAMP flg22, the reactive oxygen species (ROS) burst, which happens within minutes of flg22 application (Chinchilla et al. 2007) and can be sensitively measured with a luminol-based assay (Schwessinger et al. 2011). Relative to the WT, ald1-T2 showed reduced ROS whereas ALD1ox plants showed increased ROS after $100 \mathrm{nM}$ flg22 treatment (Fig. 2A and B). Using aniline blue staining of treated leaves, we also observed that callose deposition was similarly affected (Fig. 2C). These data show that, during basal state conditions, ALD1-dependent products affects the responsiveness to flg22 regulating ROS production.

We also monitored levels of FLS2 and its coreceptor BAK1 in plants with different levels of ALD1 by Western blot analysis of total proteins. Interestingly, ald1-T2 had reduced levels of both proteins, consistent with ALD1-dependent products regulating receptor levels (Fig. 2D). In contrast, ALD1ox did not have higher receptor levels than the WT. Possibly, a critical 
threshold level of ALD1-dependent products is needed to achieve normal receptor levels. Together, the results suggest that ALD1-dependent products regulate receptor levels and function during noninfection conditions.

\section{Responsiveness to flg22 is affected}

by more than one ALD1-dependent product.

Upon infection, vascular exudates of WT but not ald1-T2 plants accumulate Pip (Návarová et al. 2012)). We confirmed these findings (Supplementary Fig. S1). However, in uninfected plants, there was no statistically significant difference in Pip levels in WT, ald1-T2, or ALD1ox plants (Fig. 3A). One day after watering plants with $1 \mathrm{mM}$ Pip, the levels of FLS2 and BAK1 in WT or ald1-T2 plants were not affected (Fig. 3B and C). This suggests that an ALD1 basal metabolite regulates receptor levels in a Pip-independent manner.

Interestingly, Pip treatment rescued the defect in flg22induced ROS and callose accumulation in ald1-T2 (Fig. 3D and E). However, Pip did not confer increased flg22 responses to WT plants. Possibly, a metabolite made by ALD1 competes with exogenous Pip for affecting receptor-dependent events. Because ALD1ox shows enhanced flg22 responses and ALD1ox did not constitutively accumulate increased Pip levels, we infer that a non-Pip, ALD1-dependent metabolite also can modulate receptor signaling.

\section{Overexpression of ALD1 primes plants}

to more rapidly induce defenses upon $P$. syringae infection.

We have shown that ALD1ox affected the output of flg22 signaling and ALD1ox plants were more resistant to $P$. syringae. Therefore, we tested whether ALD1ox plants also had altered signaling responses to $P$. syringae. High-performance liquid chromatography and quantitative reverse-transcriptase polymerase chain reaction (RT-PCR) analysis of leaf tissue samples were used to analyze the kinetics of SA accumulation and the abundance of two defense gene transcripts, PRI and ICS1/SID2 (SA biosynthetic enzyme), respectively. Overexpression of $A L D 1$ did not alter the basal SA level in Arabidopsis leaves before infection (Fig. 4A, $0 \mathrm{~h}$ after inoculation). After infection with virulent PmaDG3, SA accumulated faster and to higher levels in leaves of ALD1ox plants than in WT plants (Fig. 4A). Transcript levels of PRI and ICS1/SID2 were induced to high levels earlier after PmaDG3 infection in leaves of ALD1ox plants than in the WT (Fig. 4B). Small increases of PRI and ICSI transcript levels (1.4and 3.4-fold, respectively, versus 228- and 38-fold $18 \mathrm{~h}$ after infection) in ALD1ox were observed in the basal, uninfected state. The effect of ALD1ox on defense activation was observed at 9 and $15 \mathrm{~h}$ postinfection but not at later times. Thus, the early robust activation of defense responses against pathogens was correlated with increased disease resistance.

The faster increase relative to the WT of SA accumulation and PRI and ICS1 transcript levels after infection in ALD1ox plants was reminiscent of the effects of treating plants with AZA, a systemic priming signal that confers increased resistance to P. syringae (Chaturvedi et al. 2012; Jung et al. 2009; Yu et al. 2013). However, unlike its effect on WT plants, AZA treatment did not make ALD1ox plants even more resistant to $P$. syringae (Fig. 4C). The nonadditive effect of ALD1ox and AZA is probably due to a common priming pathway or component being targeted by an ALD1-dependent metabolite and AZA.

\section{Pathogen resistance conferred by ALD1 requires PAD4 and ICS1/SID2, genes that are regulated by ALD1 during infection.}

$A L D 1$ transcript levels are positively regulated by SA agonist treatment and by defense components that affect SA accumulation during infection (Návarová et al. 2012; Song et al.
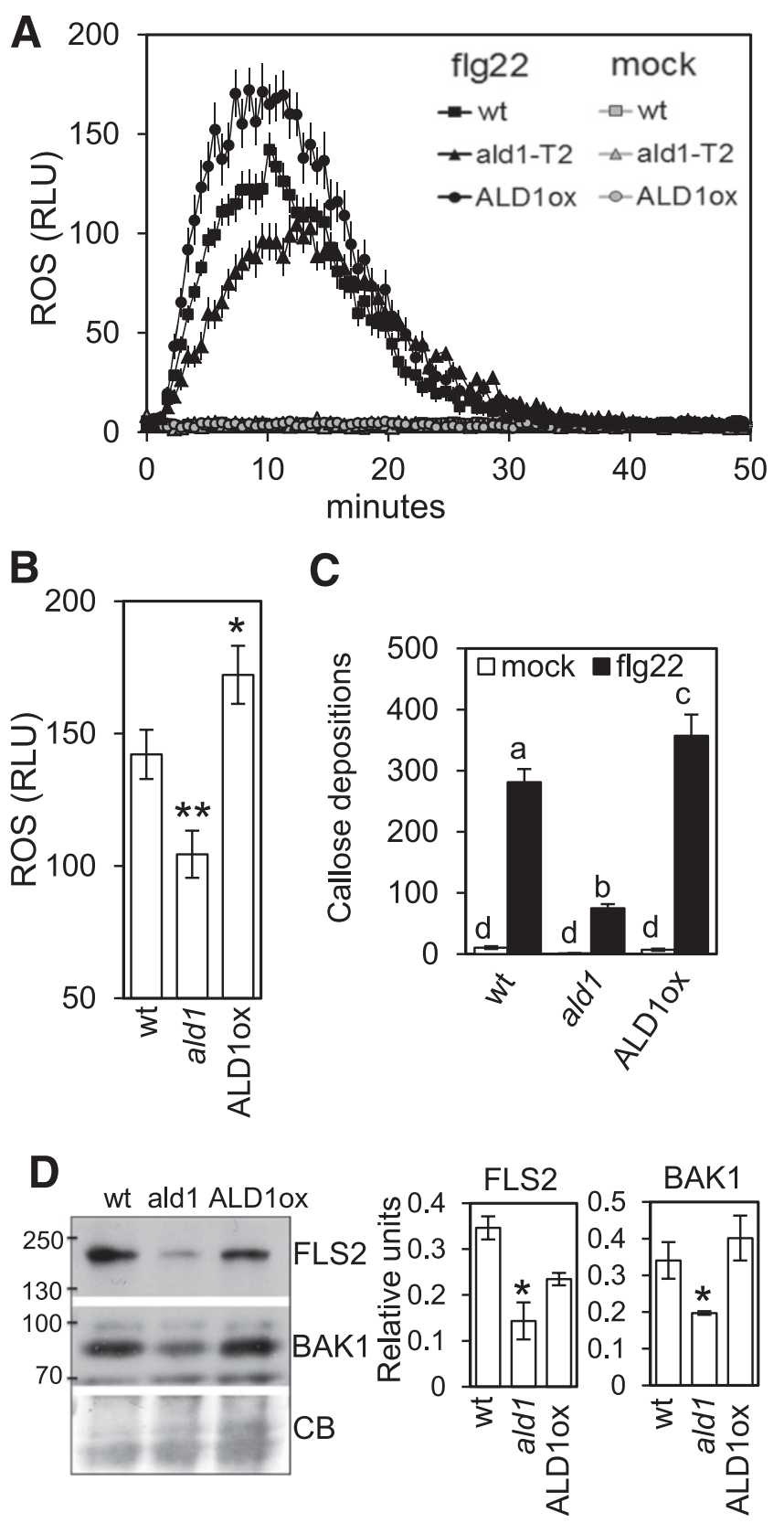

Fig. 2. Responses induced by flg 22 in ald1 mutant and $A L D 1$-overexpressor Arabidopsis plants. Pathogen-associated molecular pattern-triggered immunity responses are reduced in ald1 mutants and increased in ALD1overexpressor Arabidopsis plants. A, Reactive oxygen species (ROS) production over time of Col (wild type [wt]), ald1-T2 (ald1), and ALD1overexpressor line 8 (ALD1ox) leaf discs treated with mock or $100 \mathrm{nM}$ flg22 measured in relative light units (RLUs). B, Average of maximum ROS production from each genotype in A. Results are means with standard error from three independent experiments analyzed together (each biological replicate had $n=12$ ). Asterisks indicate statistically significant differences versus wt as determined using $t$ tests $(* * P<0.01, * P<0.05)$. C, Callose deposits quantified from indicated plants treated with mock or $1 \mu \mathrm{M}$ flg22. Number of callose deposits is shown as the average, with standard error from data obtained from three independent experiments, each with 12 biological replicates. Statistically significant differences $(P<0.01$, analysis of variance, Tukey test $)$ are shown using different lowercase letters. D, Basal FLS2 and BAK1 levels in total extracts of the indicated plants. Immunoblots were analyzed by using FLS2 and BAK1 antibodies. Blots stained with Coomassie blue (CB) are presented to show loading. Molecular weights (in $\mathrm{kDa}$ ) are indicated. Similar results were observed in three independent experiments. Right panel shows the levels of FLS2 and BAK1 relative to the total proteins (minus Rubisco) content in each CB membrane lane as quantified by densitometry. The average with standard error from three replicates are shown; * indicates significantly different from wt at a level of $P<0.05$ as determined by $t$ test. 
2004b). Thus, it seems possible that the enhanced disease resistance response of ALD1ox may depend on some or all SAbiosynthesis or regulatory factors such as ICS1/SID2, PAD4, or FMO1. To test this possibility, we introgressed the ALD1

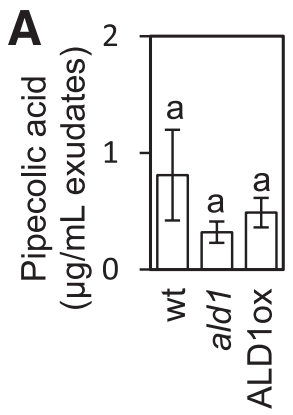

B
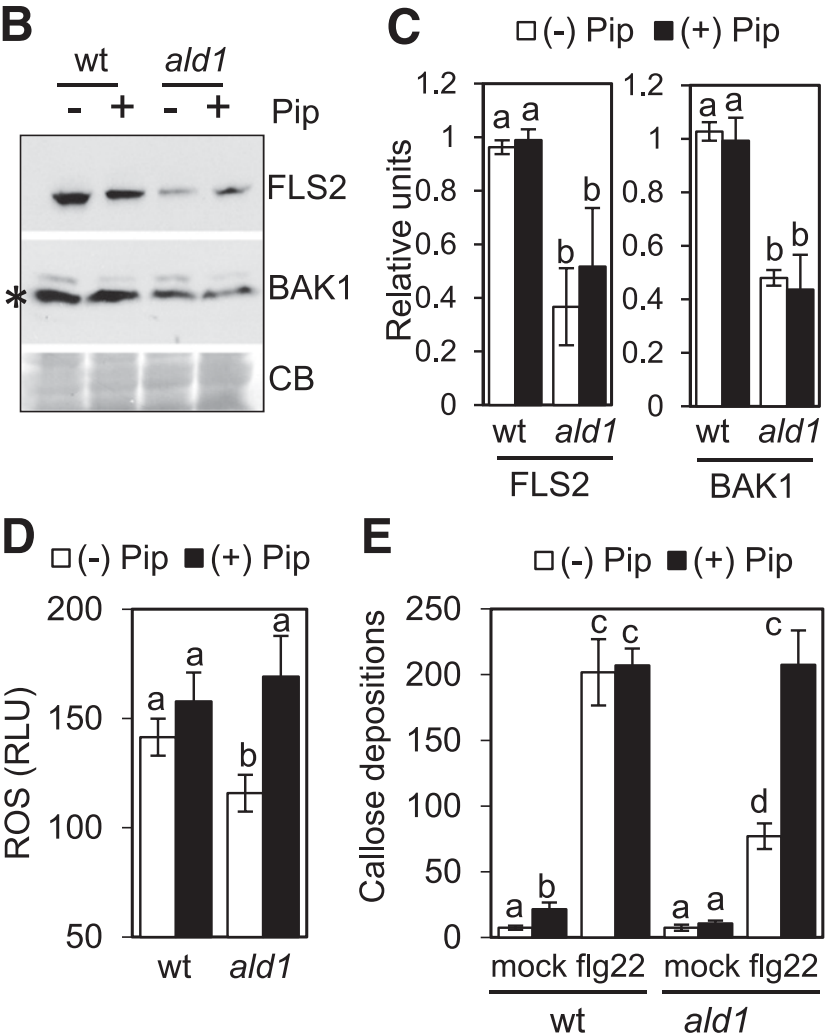

Fig. 3. Pipecolic acid (Pip) content of $A L D 1$-overexpressor plants and pathogen-associated molecular pattern-triggered immunity responses in wild-type (wt) Col-0 and ald1-T2 mutant plants $24 \mathrm{~h}$ after watering with water (-Pip) or $1 \mathrm{mM}$ Pip (+Pip). A, Pip accumulation in petiole exudates of untreated wt Col-0, aldl mutant, and ALD1ox plants in the absence of pathogen infection. Results are average, with standard error from at least two biological replicates $(n=3$ for each replicate); $\mathrm{wt}=$ three replicates, ald $1=$ two replicates, and ALD1ox $=$ four replicates. B, FLS2 and BAK1 levels in total extracts in wt Col-0 and aldl mutant plants. Immunoblots were analyzed by using FLS2 and BAK1 antibodies. Blots stained with Coomassie blue (CB) are presented to show loading. Similar results were observed in four independent experiments. * indicates the correct BAK1 band. C, Levels of FLS2 and BAK1 relative to the total proteins (minus Rubisco) content in each CB membrane lane as quantified by densitometry. Averages with standard error from four biological replicates are shown. D, Average of maximum reactive oxygen species (ROS) production of wt Col-0 and ald mutant plants leaf discs treated with $100 \mathrm{nM}$ flg22 measured in relative light units (RLUs). Bars show averages, with standard error from three independent experiments, each of which used 12 replicates. E, Callose deposits quantified from indicated plants treated with mock or $1 \mu \mathrm{M}$ flg22. Number of callose deposits is shown as the average, with standard error from three biological replicates. In $\mathrm{A}, \mathrm{C}, \mathrm{D}$, and $\mathrm{E}$, statistically significant differences $(P<0.01$, analysis of variance, Tukey test) are shown using different lowercase letters. transgene by crossing ALD1ox with sid2, pad4, and fmol mutants, and infected these plants with the virulent strain PmaDG3 to analyze bacteria growth 3 days after inoculation. Overexpression of $A L D 1$ failed to confer disease resistance against PmaDG3 infection in pad4 and sid2 plants, whereas it was still effective in fmol plants (Fig. 5A). We validated that overexpression of $A L D 1$ occurred in the WT, pad4, sid2, and fmol plants (Supplementary Fig. S2). Therefore, the increased resistance conferred by ALD1ox was dependent on PAD4 and ICS1/SID2 but not FMO1.

We also tested whether ALD1 normally regulates PAD4, ICS1/ $S I D 2$, or FMO1 during infection. To address this, we compared the accumulation of these transcripts by quantitative RT-PCR in WT, ald1-T2, and ALD1ox plants at different times postinfection with the avirulent strain PmaDG6. Indeed, ald1-T2 showed a transient reduction (at $5 \mathrm{~h}$ ) in PAD4 and ICS1/SID2 transcript levels early after infection (Fig. 5B and C). This defect did not extend to FMO1 (Fig. 5D), indicating that there was some specificity to the effect of the loss of ALD1. In agreement, PAD4 and ICS1/SID2 induction were enhanced in ALD1ox compared with WT plants (Fig. 5E and F). However, FMO1 also showed a faster induction in ALD1ox, suggesting that ALD1 may also have a local stimulatory role on this gene (Fig. 5G). Together these results indicate that ALD1 is limiting for the proper regulation of PAD4 and SID2 during infection with P. syringae.

\section{Exudates of plants overexpressing ALD1}

confer disease resistance.

The defense-related phenotypes of ALD1ox plants could be due to preexisting or accumulated ALD1-dependent basal compounds capable of conferring disease resistance. As discussed above (and see Figure 3A), although exudates from uninfected independent transgenic lines of ALD1ox plants did not have increased Pip (or higher SA) (Supplementary Fig. S3), they nevertheless conferred increased disease resistance when applied by leaf infiltration to WT plants (Fig. 6A). Local application of ALD1ox exudates did not confer increased resistance to distal leaves (Fig. 6B), suggesting the active exudate components are not highly mobile in intact plants. Alternatively, some active mobile components could be degraded before or during movement. Importantly, the ALD1ox exudate could suppress the pathogen-susceptible phenotype of the ald1-T2 mutant (Fig. 6C). It also suppressed pathogen susceptibility in fmol but not in pad4 or sid2. This suggests that PAD4 and ICS1/SID2 are needed for responding to the ALD1ox exudate. Together with the need for PAD4 and ICS1/SID2 to establish ALD1ox-mediated increased resistance (Fig. 5A), these results suggest that the ALD1 products generated during basal noninfection conditions are transduced into resistance by these two key factors.

\section{ALD1 localizes to chloroplast.}

According to the TargetP (Emanuelsson et al. 2007) subcellular prediction algorithm, $A L D 1$, like its homolog AGD2 (Song et al. 2004a), has a predicted transit peptide for targeting to chloroplast. To gain insight further into how ALD1 might contribute to defense, we studied its localization in Arabidopsis. We transformed ald1-T2 Arabidopsis plants with a construct harboring $A L D 1$ fused to green fluorescent protein (GFP) controlled by a dexamethasone (dex)-inducible promoter. The fusion protein was functional and complemented ald1-T2 mutation. This was shown by transgenic plants pretreated for $21 \mathrm{~h}$ with dex supporting reduced growth of two strains of P. syringae (Fig. 7A), to which the ald1-T2 mutant has higher susceptibility (Song et al. 2004b). ALD1:GFP predominantly colocalized with the autofluorescence of epidermal cell chloroplasts in confocal micrographs (Fig. 7B) and cofractionated with the chloroplast marker ATPase $\beta$ in chloroplast-enriched 
extracts (Fig. 7C). The presence of the cytoplasmic marker protein cytHsc70 only in total fraction indicated the purity of our fractionation. Together, these results show that ALD1 aminotransferase localizes to chloroplasts, where it likely generates amino or oxo acid-derived defense signals.

\section{ALD1-like gene of Nicotiana benthamiana is important for local and systemic resistance.}

To determine whether ALD1 is important for disease resistance in plants other than Arabidopsis, we studied its regulation and role in Nicotiana benthamiana, which has a homolog (NbALD1) with $81 \%$ similarity and $67 \%$ identity to Arabidopsis ALD1. N. benthamiana leaves infected with a virulent and avirulent derivatives of $P$. syringae pv. tabaci PTBR2004 robustly induced transcripts of $N b A L D 1$ (Fig. 8A). We employed virus-induced gene silencing (VIGS) to reduce $N b A L D 1$ expression, and infected mock-treated and $N b A L D l$-silenced plants with $P$. syringae pv. syringae B728a, a strain that grows both endophytically and epiphytically when spray inoculated on $N$. benthamiana (Lee et al. 2012; Vinatzer et al. 2006). VIGS worked well to significantly reduce $N b A L D 1$ levels in infected local and systemic leaves of $N$. benthamiana (Fig. 8C and E). $P$. syringae pv. syringae B728a grew better both on leaf surfaces (epiphytic) and in extracellular spaces (endophytic) of $N b A L D 1$-silenced plants than in nonsilenced control plants (Fig. 8B). Infection of lower leaves with $P$. syringae pv. tabaci or avrRpt2 successfully activated SAR against B728a infection in distal leaves of nonsilenced plants (Fig. 8D). However, silencing of $N b A L D 1$ abolished SAR.

These results show that $N b A L D 1$ 's role during both local and systemic defenses is similar and comparable with Arabidopsis $A L D 1$ (Song et al. 2004b) and indicate a key conserved function of these aminotransferases for pathogen defenses.

\section{DISCUSSION}

Metabolites are increasingly appreciated for their roles as modulators of diverse signaling processes in plants. ALD1 is an enzyme that can produce multiple metabolite products in vitro (Song et al. 2004a). The enzyme's broad substrate specificity combined with the gene's dynamic regulation raised the possibility that ALD1-dependent, biologically active products and their targets may differ depending on the in vivo conditions. Previously, increased Pip accumulation has been shown to be ALD1-dependent during infection, and exogenous Pip treatment boosted disease resistance. Here, we present data that argue for additional basal state products, generated by ALD1 during noninfection conditions, that are also biologically active in defense regulation. First, the level of flg22-induced ROS accumulation increased in proportion to the level of ALD1 in plants, although plants with different amounts of ALD1 did not differ in their basal Pip levels. The ROS response was much faster than the time needed for Pip to accumulate (Návarová et al. 2012), implying that a basal, non-Pip metabolite affected the ROS response. Second, ALD1ox plants conferred disease resistance without producing additional Pip and exudates of ALD1ox were sufficient to confer disease resistance to WT plants. Together, our results indicate that ALD1 makes more than one biologically active product and, furthermore, one or more of them acts in a very early defense response.

During infections, plants reprogram their metabolism and increase the production of many compounds and antimicrobial molecules as well as defense signals. In agreement with the idea that in vivo ALD1 could produce more than one defense metabolite, our ALD1ox petiole exudate mass spectrometry (MS) analyses showed novel metabolites whose levels are increased relative to the WT but whose identities are unknown due to their
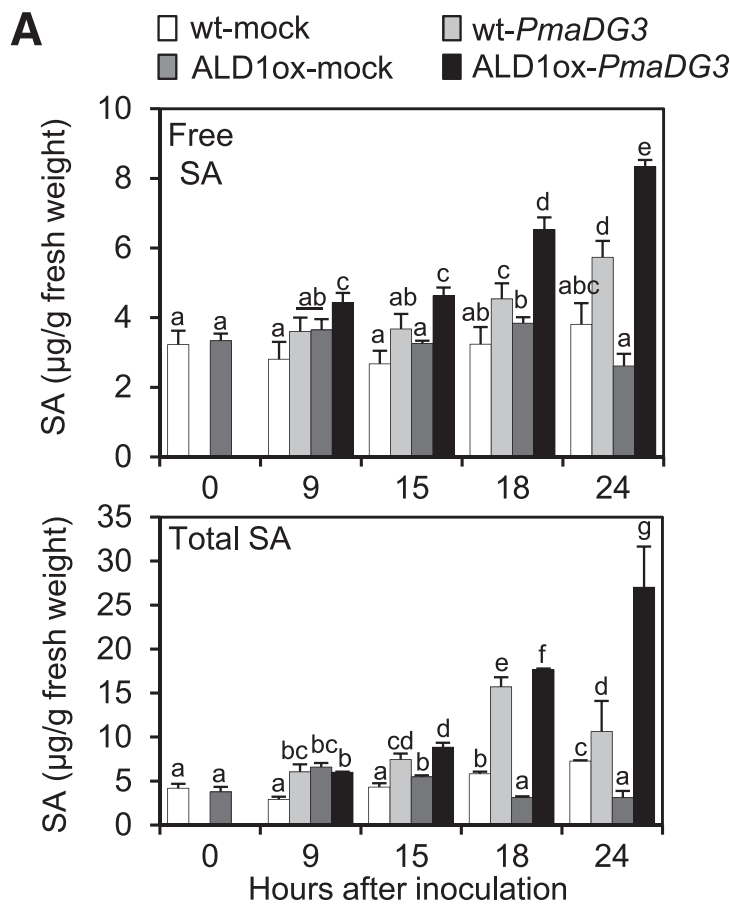

B $\square$ wild type $\operatorname{ALD10x}(\# 8)$
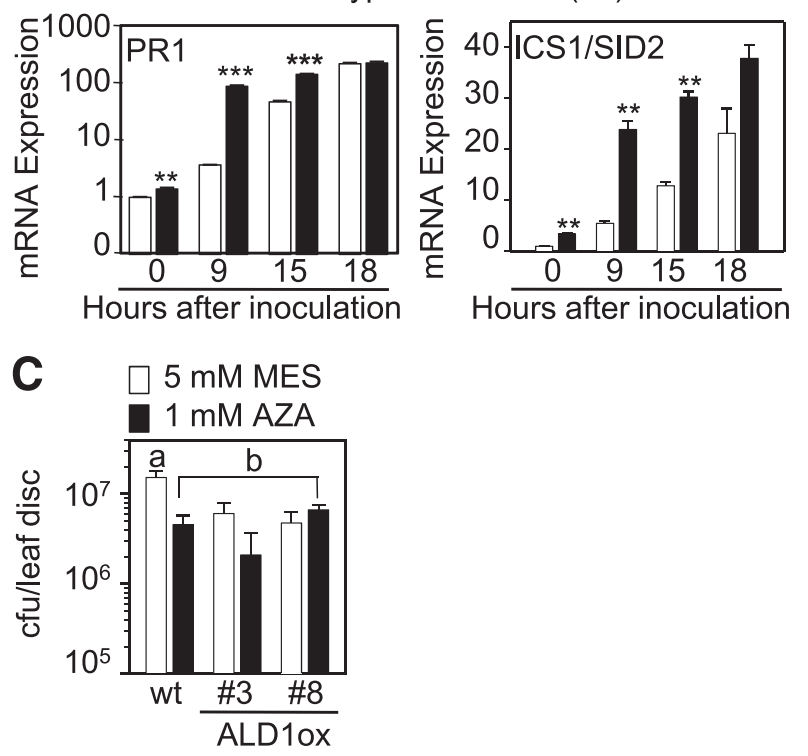

Fig. 4. Salicylic acid (SA)-dependent inducible defense of ALD1ox Arabidopsis plants. A, Increased free or total SA levels in leaves of ALD1ox (line 8) plants during mock inoculation $\left(1 \mathrm{mM} \mathrm{MgSO}_{4}\right)$ or infection with Pseudomonas syringae pv. maculicola ES4326 carrying empty vector (PmaDG3) $\left(\mathrm{OD}_{600}=0.01\right) ; \mathrm{wt}=$ wild type. Error bars indicate standard deviation from three biological replications $(n=3)$. Different letters indicate statistical differences among the different samples at given time points $(P<0.01$, analysis of variance [ANOVA], Tukey test). B, PR1 and ICS1/SID2 mRNA levels in leaves of ALD1ox (line 8) during PmaDG3 infection. Leaves of the wild type (white) or ALD1ox (black) were taken at the indicated times after mock treatment or PmaDG3 infection. Error bars indicate standard deviation from three technical replicates $(n=3)$. Asterisks indicate statistically differences in expression level between wild type and ALD1ox plants at given time points (** and *** indicate $P<0.01$ and 0.001 , respectively; Student's $t$ test). Experiments shown in A and B were repeated four times with similar results. C, Pretreatment of azelaic acid (AZA), a defense-priming inducing signal, could not render ALD1ox plants hyper-resistant against PmaDG3 infection. At 2 days prior to PmaDG3 inoculation $\left(\mathrm{OD}_{600}=0.0001\right), 5 \mathrm{mM}$ morpholineethanesulfonic acid (MES) (white) and $1 \mathrm{mM}$ AZA in $5 \mathrm{mM}$ MES (black) were sprayed on the plants. Different letters indicates statistically significant differences $(P<0.01$, ANOVA, Tukey test). Error bars indicate standard error $(n=6$ or 8$)$. The experiment was repeated twice with similar results. 


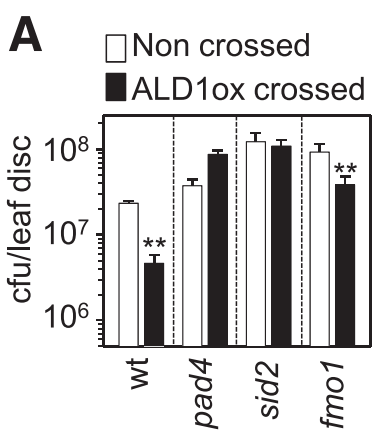

B
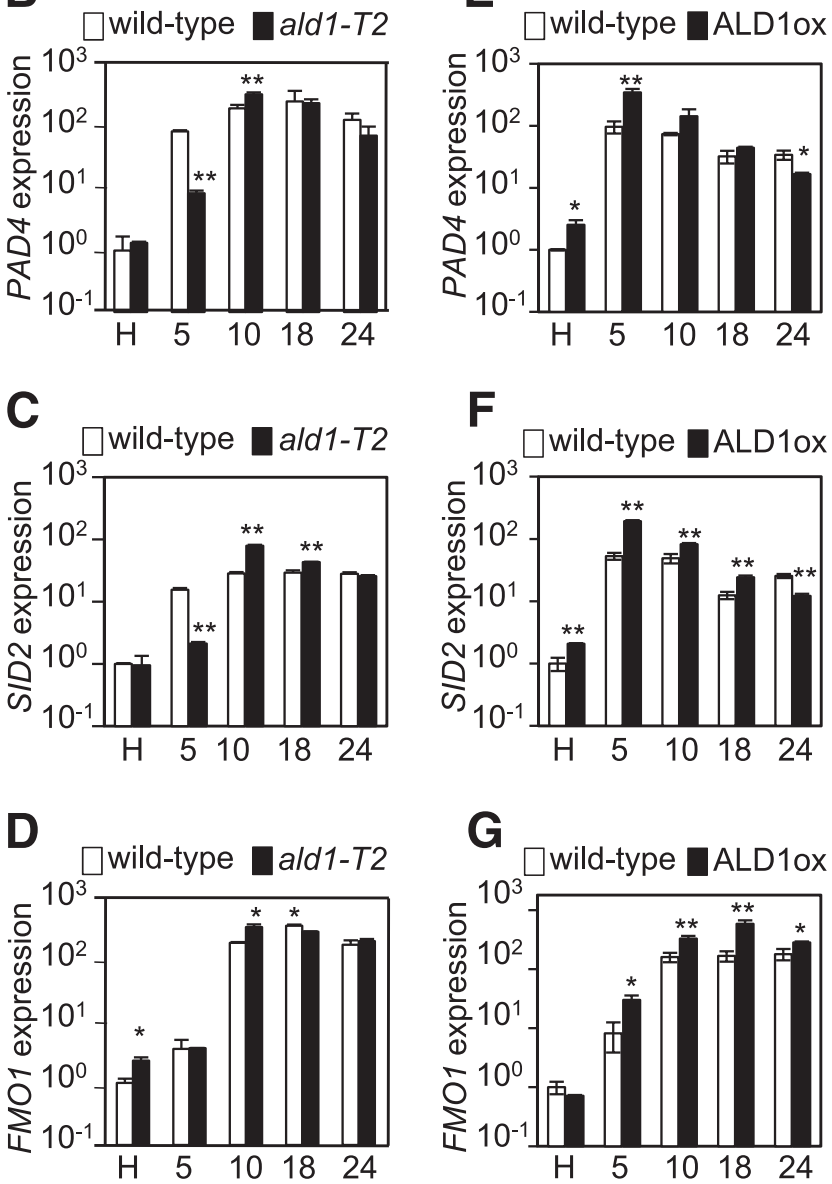

Fig. 5. Relationship between ALD1 and other salicylic-acid-related defense regulators. A, ALD1 required PAD4 and ICS1/SID2 but not FMO1 to confer disease resistance. The number of bacteria in wild-type Col-0 or indicated single mutants (white) or the indicated single mutants crossed with ALD1ox (line 8) plants (black) were measured on day 3 after infection with a virulent strain Pseudomonas syringae pv. maculicola ES4326 carrying empty vector $(P m a D G 3)\left(\mathrm{OD}_{600}=0.0001\right)$. Error bars indicate standard error $(n=6$ or 8$)$. The experiment was repeated at least two times for each background with similar results. Asterisks indicate statistically significant differences between ALD1ox crossed or noncrossed plant (** $P<0.01$, $t$ test). Bacterial growth for each background should be compared with those of the same genotype, because different genotypes were grown separately (dotted divisor lines). B to $\mathbf{G}$, Defense gene expression dependent on ALD1 during infection. Relative expression of $\mathbf{B}$ and E, PAD4; $\mathbf{C}$ and F, SID2; and $\mathbf{D}$ and $\mathbf{G}, F M O 1$ in the wild type; $\mathbf{B}$ to $\mathbf{D}$, the ald1-T2 mutant and $\mathbf{E}$ and $\mathbf{G}$, wild-type and ALD1ox plants. Infected local leaves were taken at the indicated times after infection of an avirulent derivative of $P$. syringae pv. maculicola ES4326 carrying avrRpt 2 (PmaDG6) $\left(\mathrm{OD}_{600}=0.01\right)$. Error bars in $\mathrm{B}$ to $\mathrm{G}$ indicate standard deviation from three technical replicates. Asterisks indicate statistical differences in expression level between wild-type Col-0 and ald1-T2 mutant at given time points $(P<0.01$, Student's $t$ test). All experiments were repeated at least twice with similar expression pattern. H, Noninoculated healthy plants. absence from mass spectral libraries. Their purification will be necessary for their structures to be determined. It is possible that an ALD1-unique product could be used downstream to generate different defense metabolites depending on conditions (e.g., whether or not a pathogen is present). ALD1 may produce metabolites with different targets such as PTI or later infection responses. Defense-related metabolic pathways producing different products are known. An example is the shikimate pathway, where the shikimic acid product is used to generate an array of different defense-related metabolites and signals, including SA (Verberne et al. 2007; Vogt 2010).

If it is not Pip, what is the ALD1 metabolite acting during basal noninfection conditions? As an aminotransferase, we expect ALD1 to generate amino-acid-derived compounds. Amino acids, aminotransferases, and amino-acid-derived molecules are involved in the synthesis of secondary metabolites known to be important as antimicrobials (Namwat et al. 2002; Sønderby et al. 2010) and defense signals (Adio et al. 2011; Cecchini et al. 2011; Lerich et al. 2012; Liu et al. 2010; Návarová et al. 2012; Stuttmann et al. 2011; Taler et al. 2004; van Damme et al. 2009). Moreover, amino acid conjugates, particularly to hormones, play essential roles in physiologic processes, including plant defenses (Ljung et al. 2002; Okrent and Wildermuth 2011; Piotrowska and Bajguz 2011; von Saint Paul et al. 2011). Additionally, ALD1's chloroplastic localization could also have great impact in defense metabolic pathways, considering that this organelle is a factory of amino acids, secondary metabolites, and phytohormones such as SA (Bryan 1990; Wildermuth et al. 2001).

We show here that ALD1 is necessary for normal production of the FLS2 receptor and its coreceptor BAK1 but may work only up to some threshold level, such that producing even more ALD1 does not confer higher receptor levels but induces increased PTI responses. Although increasing FLS2 levels was shown to be a way to increase flg22 responsiveness (GómezGómez and Boller 2000), our results show that other modes of altering responsiveness exist. It is possible that more than one ALD1 product is affecting different components of the FLS2 receptor complex. A basal state metabolite could be acting to maintain receptor levels and another metabolite may regulate responsiveness. Alternatively, the same metabolite could be regulating different components of the FLS2 complex. Interestingly, it has recently been shown that the responses to the endogenous DAMP Pep2 are reduced in ald1-T2 mutant (Ross et al. 2014). Considering this, an attractive possibility is that ALD1 products may be affecting shared PRR complexes' components such as SERKs, BIK1s, or NADPH oxidases (Kadota et al. 2014; Li et al. 2014; Macho and Zipfel 2014; Roux et al. 2011). If this is true, ALD1 may regulate more than one PRR complex and their responses.

Pip treatment can increase resistance against virulent and avirulent bacterial infections in ald1-T2 and WT plants (Návarová et al. 2012). However, it is striking that Pip does not similarly affect flg22-triggered responses, and only compensates for them when ALD1 is missing. This suggests that Pip's effect on PTI is due to a different mechanism than the one acting during defenses induced after infections. In any case, why does Pip only compensate PTI fast responses in the ald1-T2 mutant without affecting them in WT plants? One idea to explain this is that an inhibition or competition exists between ALD1 basal state metabolites and Pip. An alternative explanation could be that an excess of exogenously added Pip could be metabolically redirected to new active metabolites only when ALD1 is not present. These possibilities show the complexity of resistance program networks. Defense-related enzymes with many substrates or products, such as ALD1, could provide the necessary fine control to tune defense programs. 
Upon infection, ALD1ox showed an early trigger of free SA accumulation that was correlated with SA signaling, as indicated by $P R 1$ induction. Conversely, ald $1-T 2$ mutant plants showed slower induction of SA and PRI (Song et al. 2004b). The higher resistance to infection in ALD1ox supports the idea that early defense responses drive the output of plant pathogen interactions (Feys et al. 2001; Glazebrook et al. 1996, 1997, 2003; Gupta et al. 2000; Shapiro and Zhang 2001; Zhou et al. 1998). This ALD1-dependent primed state may reflect the action of ALD1produced compounds that sensitize defense components to produce stronger responses upon stimulus. Interestingly, two well-characterized priming signals, AZA and $\beta$-aminobutyric acid (Jung et al. 2009; Zimmerli et al. 2000), are not effective on ald1 mutant plants (Jung et al. 2009; Návarová et al. 2012). Additionally, the effects of ALD1ox and AZA are nonadditive, suggesting a common priming pathway. In agreement, it was shown that AZA primes SA accumulation and PRI induction (Jung et al. 2009; Yu et al. 2013). Furthermore, it was recently reported that AZA production depends on ROS increases (Wang et al. 2014). Because ALD1 has a positive effect on ROS

A $\square$ wt-exudates
$\square$ ALD10x-exudates

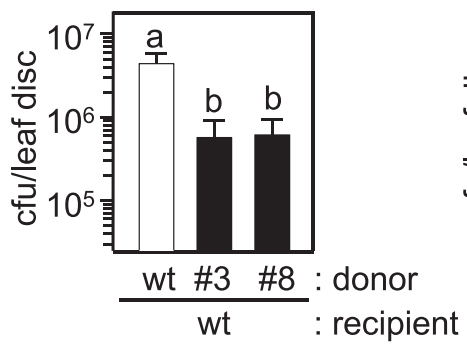

B $\square$ wt-exudates
ALD10x-exudates
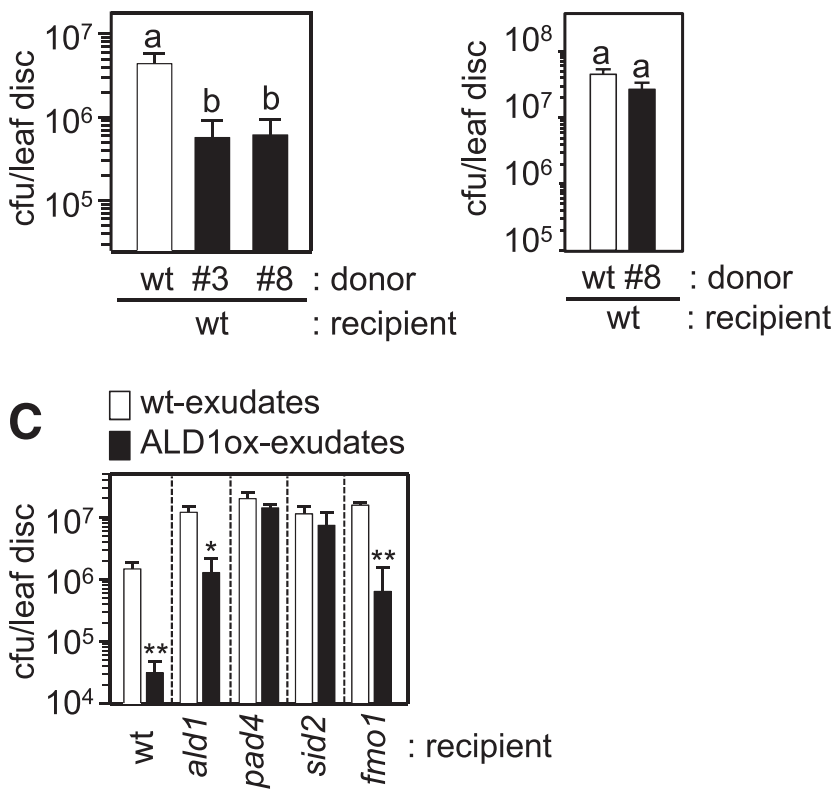

Fig. 6. Biological activity of petiole exudates from untreated ALD1ox plants. A, Petiole exudates from $A L D 1$ overexpressor line 3 and 8 (ALD1 ox) plants inhibited the growth of a virulent Pseudomonas syringae pv. maculicola ES4326 carrying empty vector $(P m a D G 3)\left(\mathrm{OD}_{600}=0.0001\right)$ in the leaves of wild-type (wt) plants in which they were applied prior to pathogen infection. The inoculation studies were repeated six times, with similar results in five of the six trials. B, Exudates from ALD1ox could not induce systemic resistance against PmaDG3 in the distal leaves of recipient wt plants locally preinfiltrated with ALD1ox-exudates (line 8). Similar results were found in three biological replicates. Error bars indicate standard error (A and B). Different letters indicate statistical differences among the different samples $(P<0.01$, analysis of variance, Tukey test). C, ALD1ox exudates rescued hypersusceptibility phenotype of ald 1 and fmol but not sid 2 or pad 4 mutants. Petiole exudates from wt Col-0 leaves (white) and from ALDlox (black) were pretreated into leaves of indicated mutant plants 2 days prior to pathogen infection. The number of bacteria was measured on day 3 after infection with a virulent strain of PmaDG3 $\left(\mathrm{OD}_{600}=0.0001\right)$. This experiment was repeated three times with similar results. Error bars indicate standard error. Different numbers of asterisks indicate statistically significant differences between wt or ALD1oxvexudates treatments $(*$ and $* *$ indicate $P<0.05$ and 0.01 , respectively; $t$ test). Bacterial growth for each background should be compared with those of the same genotype, because different genotypes were grown separately (dotted divisor lines). generation during PTI, it is also possible that ALD1 indirectly affects AZA accumulation or priming during this defense program. Together, these observations support an important role for ALD1 in the priming establishment mechanisms.

It is probable that one of the ALD1 metabolites capable of priming defenses is Pip. However, because ALD1 can also produce active exudates that do not have elevated Pip levels, another product could transduce signals into primed defenses. In agreement, treatments with ALD1ox petiole exudates can induce resistance. In this case, and contrary to what is proposed for Pip, the effect of ALD1-exudate metabolites is only local; it cannot induce resistance in systemic leaves. An interesting idea is that the ALD1ox effect is partially mimicking a distal tissue during the SAR-primed state (i.e., some non-Pip metabolite might accumulate).

PAD4 and ICS1/SID2 but not FMO1 are needed to establish increased resistance in ALD1ox. Importantly, the same defense components are needed in recipient plants to respond to
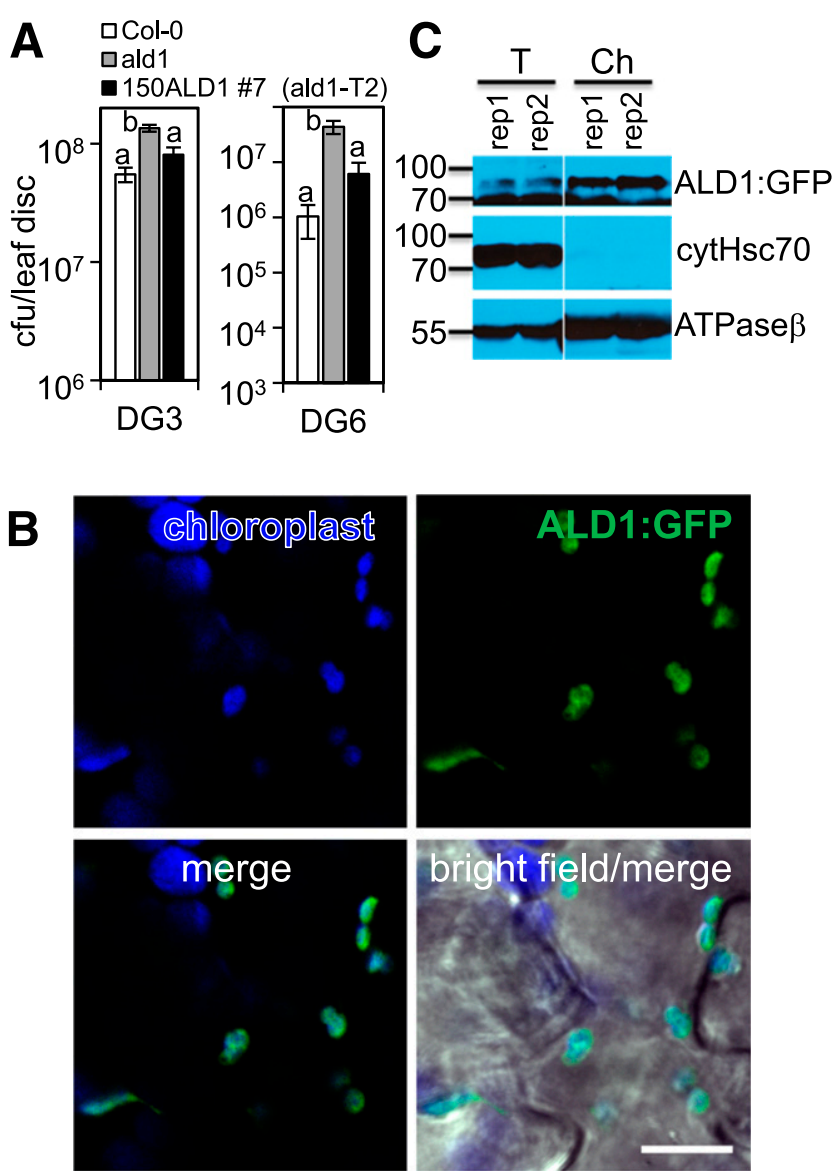

Fig. 7. AtALD1:green fluorescent protein (GFP) fusion protein is targeted to chloroplast of Arabidopsis leaves. A, Complementation of the ald1-T2 mutant (ald1) disease susceptibility with AtALD1:GFP protein controlled by dexamethasone (dex)-inducible promoter (ALD1:GFP [ald1]) used to study ALD1 localization. This experiment was repeated three times with similar results. Error bars indicate standard error $(n=8)$. Letters show statistically significant differences between the indicated plants infected with virulent $P$ seudomonas syringae pv. maculicola ES4326 carrying empty vector (PmaDG3) and avirulent $P$. syringae pv. maculicola carrying avrRpt2 (PmaDG6) $(P<0.01$, analysis of variance, Tukey test). B, Laser-scanning confocal microscopy micrographs showing localization of ALD1:GFP controlled by dex-inducible promoter in transgenic Arabidopsis seedlings. GFP fluorescence is shown in green and chlorophyll autofluorescence is shown in blue. Bar $=10 \mu \mathrm{m}$. C, Western blots of total $(\mathrm{T})$ and chloroplast (Ch) fractions proteins from ALD1:GFP transgenic Arabidopsis seedlings. Bands were revealed using anti-GFP, ATPaseB (chloroplast marker), and cytHsc70 (cytosolic marker) antibodies. Adult or seedlings plants were sprayed with dex $30 \mu \mathrm{M}$ solution $21 \mathrm{~h}$ before analysis or infection (A to C). 

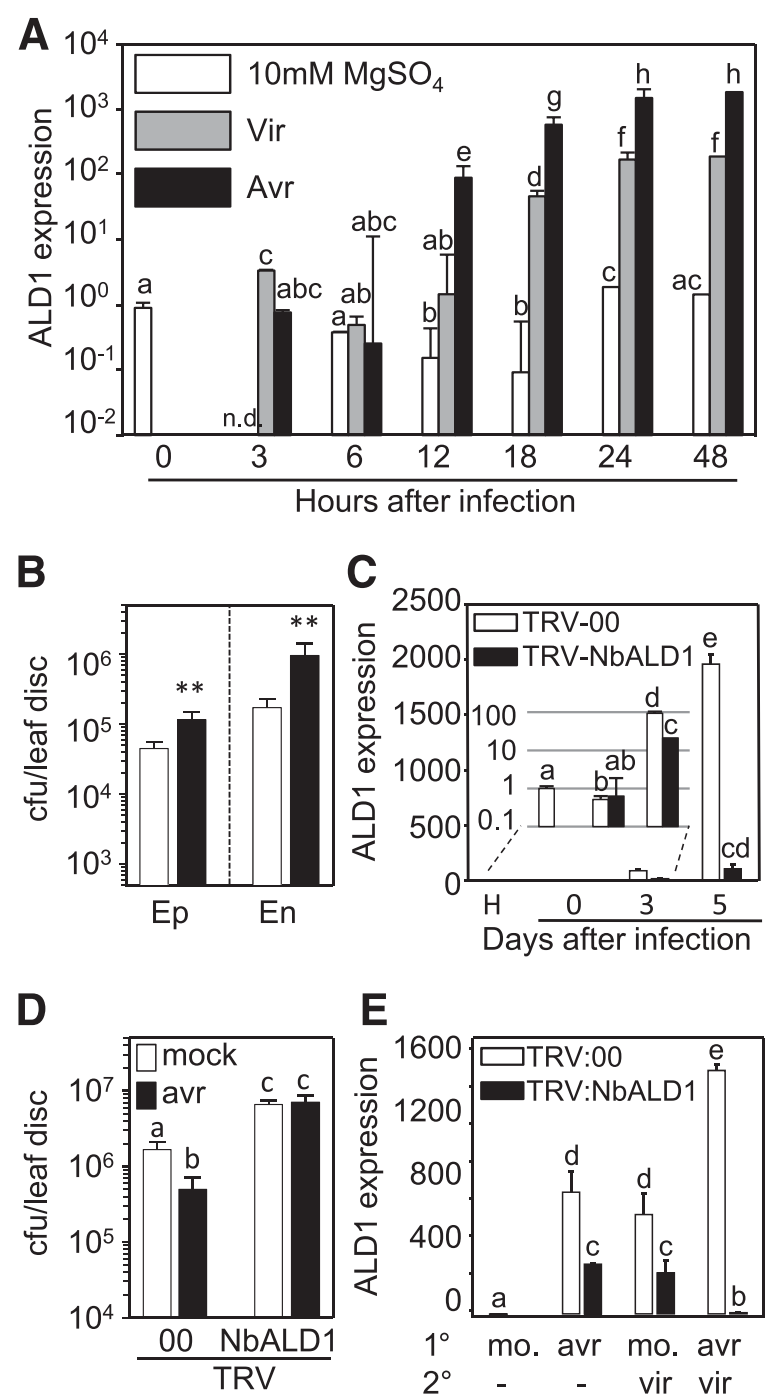

Fig. 8. NbALD1 gene of Nicotiana benthamiana is involved in both local and systemic resistance against Pseudomonas syringae infection. A, Transcription of $N b A L D 1$ gene was strongly induced in the leaves by infection with P. syringae pv. tabaci PTBR2004. Leaves syringe inoculated with mock $(10 \mathrm{mM}$ $\mathrm{MgSO}_{4}$ ) or infected with virulent $P$. syringae pv. tabaci (Vir) or avirulent derivative $P$. syringae pv. tabaci carrying avrRpt2 (Avr) $\left(\mathrm{OD}_{600}=0.01\right)$ were harvested at the indicated times after treatments. $\mathbf{B}, N b A L D 1$-silenced plants showed enhanced disease susceptibility to $P$. syringae in local leaves. Nonsilenced (white) and $N b A L D 1$-silenced (black) plants were spray inoculated with $P$. syringae pv. syringae $\mathrm{B} 728 \mathrm{a}\left(\mathrm{OD}_{600}=0.01\right)$. Both epiphytic $(\mathrm{Ep})$ and endophytic (En) bacterial population were higher on day 5 after inoculation in $N b A L D 1$-silenced plants compared with those in nonsilenced plants. C, Expression of $N b A L D 1$ was suppressed in $N b A L D 1$-silenced plants. Inset: expression of $A L D 1$ is plotted on a log scale. $\mathbf{D}, N b A L D 1$-silenced plant is systemic acquired resistance defective. Nonsilenced (TRV:00; Tobacco rattle virus [TRV]-based virus-induced gene silencing [VIGS] empty vector) and silenced plants (TRV:NbALD1; VIGS-vector carrying NbALD1 fragment) were immunized by syringe infiltration of $10 \mathrm{mM} \mathrm{MgSO}_{4}$ (white) or P. syringae pv. tabaci carrying avrRpt $2\left(\mathrm{OD}_{600}=0.01\right)$ (black) 3 days prior to secondary $P$. syringae pv. syringae $\mathrm{B} 728$ a infection by spray inoculation $\left(\mathrm{OD}_{600}=0.01\right)$. The number of bacteria was examined 5 days after inoculation. $\mathbf{E}$, Transcript levels of $N b A L D 1$ were increased in systemic leaves of nonsilenced plants (white) immunized with avrRpt 2 but not in NbALD1-silenced plants (black). Primary immunization $\left(1^{\circ}\right)$ and secondary challenge $\left(2^{\circ}\right)$ were done as in $\mathrm{D}$; avr $=P$. syringae pv. tabaci carrying avrRpt 2 , mo $=$ mock $(10 \mathrm{mM} \mathrm{MgSO} 4)$, and vir = B738a. Samples were collected 3 days after secondary challenge inoculation. Error bars indicate standard error in B and D $(n=18$ or 24$)$ and standard deviation in A, C, and E $(n=3)$. Asterisks in B indicate statistically significant differences relative to nonsilenced plants $(P<$ 0.01 , Student's $t$ test). Different letters in other panels indicate statistically significant differences as determined by $P<0.01$, analysis of variance, Tukey test. All experiments were repeated two or three times with similar results. The panels show one representative result among them.
ALD1ox exudate. This suggests that ALD1 function requires the action and regulation of major genes already known to be important for $P$. syringae resistance, PAD4 and ICS1/SID2 (Glazebrook et al. 1996; Wildermuth et al. 2001). It also suggests that a basal state ALD1 product is transduced into resistance by these factors. In contrast, PAD4 and FMO1 are needed for Pip to fully increase resistance, whereas ICS1/SID2 is needed only partially (Návarová et al. 2012). Moreover, Pip accumulation after local infection depends on PAD4 but not on ICS1/SID2 or FMO1. Again, these differences between ALD1 basal state metabolites and Pip support the idea of ALD1 producing more than one defense metabolite.

Previously, we have shown that $A L D 1$ induction depends mainly on PAD4 and, under certain conditions (in acd6-1 plants that constitutively produce SA and high transcript levels of $A L D 1$ and PAD4) (Lu et al. 2003), ALD1 weakly affects PAD4 transcript levels (Song et al. 2004b). Here, we show that, at early times ( $5 \mathrm{~h}$ ) after infection, PAD4 and ICS1/SID2 induction strongly depend on ALD1. In addition, $A L D 1$ overexpression enhances the induction of both transcripts. Altogether, the transcriptional interdependence between these components suggests that an amplification loop exists between ALD1PAD4-ICS1/SID2. In agreement with this, SA and its agonist benzo $(1,2$, and 3$)$ thiadiazole-7-carbothioic acid (BTH) can induce ALD1 (Návarová et al. 2012; Song et al. 2004b). FMOI is also stimulated by $A L D 1$ overexpression. However, because FMO1 is not necessary for ALD1ox-conferred increased resistance, it does not appear to have a role in local resistance. Supporting this, a similar loop between ALD1-ICS1 and SID2FMO1 was suggested to work in systemic leaves during SAR establishment (Návarová et al. 2012). Here, we propose that an ALD1-PAD4-ICS1/SID2 loop accelerates SA-related defenses locally and at early times postinfection. Considering the effect of ALD1 on flg22 responses, it is possible that PTI components are also part of the ALD1-dependent defense amplification loop. In support of this idea, it is known that SA or BTH can potentiate PTI (Kohler et al. 2002; Sato et al. 2010; Yi et al. 2014) and increase MAMP receptor levels at the plasma membrane (Zhang et al. 2014). It is also known that ICS1/SID2 and PAD4 affect and are part of a network necessary for triggering a robust PTI (Tsuda et al. 2009, 2008). Thus, it is probable that, during early defense responses, there exists an SA-pathway amplification loop involving PTI components.

In summary, increased or decreased ALD1 affects earlier defense events than were previously described (Song et al. 2004a,b), as exemplified by altered ROS production after flg22 treatment. We speculate that the ALD1 effect could be due to a direct or indirect modulation of PTI and SA early-pathway components by chloroplastic ALD1-produced amino-acidderived compounds. These compounds are likely to be conserved in other plants, because ALD1 homologs in Lotus japonicus (Chen et al. 2014) and N. benthamiana are also important in defense pathways.

\section{MATERIALS AND METHODS}

Plants.

All Arabidopsis plants were in the Columbia-0 background. Arabidopsis plants were grown under 12-h day (8:00 A.M. to 8:00 P.M.) and 12 -h night conditions at $20^{\circ} \mathrm{C}$, as described (Greenberg et al. 2000). Arabidopsis ald1-T2, fmol, npr1-1, pad4-1, and sid2-1 were previously described (Cao et al. 1994; Glazebrook et al. 1996; Jung et al. 2009; Mishina and Zeier 2006; Nawrath and Métraux 1999; Song et al. 2004a).

The coding region of Arabidopsis ALDl was amplified with PCR primers linked to specific sequences compatible with the GATEWAY cloning procedure (Supplementary Table S1) and 
introduced into plant expression vectors pGWB20, kindly provided by Dr. Jeff Dangl (University of North Carolina), and pBAV150 (Vinatzer et al. 2006). The resulting plasmids allow the expression of $A L D 1$ with the C-terminal myc epitope tag controlled by the CaMV 35 S promoter (pGWB20) or with the C-terminal GFP tag controlled by the dex-inducible promoter (pBAV150). Transgenic plants were established by dipping WT or aldl mutant flowers into suspensions of Agrobacterium tumefaciens strain GV3101 harboring the pGWB20::ALD1 or pBAV150:ALD1 (Clough and Bent 1998), then selected in Murashige and Skoog media (Sigma-Aldrich) supplemented with kanamycin $(50 \mu \mathrm{g} / \mathrm{ml})$ and hygromycin $(50 \mu \mathrm{g} / \mathrm{ml})$ or Basta $(10 \mu \mathrm{g} / \mathrm{ml})$, respectively. To generate the mutant plants overexpressing $A L D 1$, a homozygous transgenic ALD1ox plant (pGWB20::ALD1/line 8) was crossed with pad4, sid2, and fmol. Homozygous plants were selected in the $\mathrm{F}_{2}$ generation.

\section{VIGS.}

A 447-bp fragment that corresponds to nucleotides 855 to 1,301 of $N$. benthamiana ALD1 mRNA (NbALD1; TC23014, The Gene Indices) was amplified from cDNA and cloned into the pTRV2 vector (Liu et al. 2002). The VIGS assay was performed as described by Liu and associates (2002).

\section{Pathogen infection.}

To analyze bacterial growth in Arabidopsis, leaves of 23- to 25-day-old plants were infected by syringe infiltration with a virulent derivative of $P$. syringae pv. maculicola ES4326 carrying an empty vector (PmaDG3) (optical density at $600 \mathrm{~nm}$ $\left.\left[\mathrm{OD}_{600}\right]=0.0001\right)($ Guttman and Greenberg 2001). Growth was determined 3 days after inoculation. For local gene expression studies in ald1 and SA-dependent defense mutants, leaves were infected with an avirulent derivative of $P$. syringae pv. maculicola ES4326 carrying avrRpt2 $\left(\right.$ PmaDG6) $\left(\mathrm{OD}_{600}=0.01\right)$ (Guttman and Greenberg 2001). The biological activity of petiole exudates (see Petiole Exudate Collection, below) to confer disease resistance was examined by syringe infiltration of exudates into leaves of the WT or mutants 2 days prior to subsequent pathogen infection (Jung et al. 2009). Transgenic Arabidopsis/pBAV150::ALD1 plants were sprayed with $30 \mu \mathrm{M}$ dex plus $0.1 \%$ Tween 20 solution 21 h before PmaDG3 and PmaDG6 syringe inoculations.

For $N$. benthamiana infections, plants were grown under 12-h day (8:00 A.M. to 8:00 P.M.) and 12-h night conditions at $24^{\circ} \mathrm{C}$ (Vinatzer et al. 2006). To examine expression of $N b A L D 1,5-$ week-old tobacco plants were syringe inoculated with a virulent strain of $P$. syringae pv. tabaci PTBR2004 or an avirulent derivative of $P$. syringae pv. tabaci carrying avrRpt $2\left(\mathrm{OD}_{600}=\right.$ 0.01 ) (Vinatzer et al. 2006). The bacterial strain of $P$. syringae pv. syringae $\mathrm{B} 728 \mathrm{a}\left(\mathrm{OD}_{600}=0.01\right)$ (Vinatzer et al. 2006) was sprayed on $N$. benthamiana leaves to evaluate bacterial epiphytic and endophytic growth after 5 days, as described previously (Lee et al. 2012). For SAR experiments, lower leaves of nonsilenced or $N b A L D 1$-silenced plants were immunized with P. syringae pv. tabaci carrying avrRpt $2\left(\mathrm{OD}_{600}=0.01\right) 3$ days prior to secondary $\mathrm{B} 728 \mathrm{a}$ infection $\left(\mathrm{OD}_{600}=0.01\right)$.

\section{Exogenous application of Pip and AZA.}

These treatments were done as previously described (Jung et al. 2009; Návarová et al. 2012).

\section{Petiole exudate collection.}

Leaves of 25-day-old WT, ald1-T2, or ALD1ox plants were excised and petioles submerged in $1 \mathrm{mM}$ EDTA solution supplemented with carbenicillin at $50 \mu \mathrm{g} / \mathrm{ml}$ and streptomycin for $72 \mathrm{~h}$. To eliminate residual bacteria, the petiole exudates were centrifuged three times at $12,000 \mathrm{rpm}$ for $10 \mathrm{~min}$, and the cleared exudates were plated onto Luria-Bertani media to verify the lack of bacteria. Bacteria-free petiole exudates were immediately frozen and stored at $-75^{\circ} \mathrm{C}$ until application to plants. Mockinduced exudates and pathogen-induced exudates from leaves of WT and aldl plants were infected and harvested as described previously (Jung et al. 2009).

\section{mRNA analysis.}

Total RNA isolation and reverse transcription were done using Trizol reagent and Superscript II reverse transcription, respectively, according to the manufacturer's procedures (Invitrogen). Quantitative real-time RT-PCR was performed as described previously (Jung et al. 2009). Internal standards used for data normalization were EFl $\alpha$ and ACT1 for Arabidopsis and $N$. benthamiana, respectively. Oligonucleotide sequences used as primers are presented in Supplementary Table S1.

\section{Determination of SA and AZA treatment.}

These experiments were done as described previously (Jung et al. 2009; Seskar et al. 1998).

\section{Determination of Pip.}

Exudates were trimethylsilyl (TMS) derivatized and analyzed by gas chromatography-MS, as described previously (Jung et al. 2009), with some modifications. Sorbitol (15 $\mu$ l of aqueous solution at $1 \mathrm{mg} / \mathrm{ml}$ ) was added as an internal standard to 250 to $400 \mu \mathrm{l}$ of thawed exudate, with samples then dried in a nitrogen stream. The internal standard was added to correct for differences in derivatization efficiency and changes in sample volume during heating. Dried exudates were dissolved in $500 \mu \mathrm{l}$ of silylation-grade acetonitrile followed by the addition of $500 \mu \mathrm{l}$ of $\mathrm{N}$-methyl trimethylsilyltrifluoroacetamide with $1 \%$ trimethylchlorosilane (Thermo Scientific, Bellefonte, PA, U.S.A.), and samples were then heated for $1 \mathrm{~h}$ at $70^{\circ} \mathrm{C}$ to generate TMS derivatives. After 1 to 3 days, 1 - to $2-\mu 1$ aliquots were injected into an Agilent 7890A gas chromatograph (Agilent Technologies, Santa Clara, CA, U.S.A.) coupled to an Agilent 5975C inert XL mass spectrometer (Agilent Technologies), fitted with an Rtx-5MS (crosslinked 5\% PH ME Siloxane) capillary column (30 m by $0.25 \mathrm{~mm}$ by $0.25 \mu \mathrm{m}$ film thickness) (Restek, Bellefonte, PA, U.S.A.). The standard quadrupole gas chromatograph mass spectrometer was operated in electron impact $(70 \mathrm{eV})$ mode, with 2.5 full-spectrum (50 to $650 \mathrm{Da}$ ) scans per second. Carrier gas (helium) flow was set at $1.3 \mathrm{ml} / \mathrm{min}$ with an injection port configured in the splitless mode. The injection port, MS source, and MS quadrupole temperatures were set to 250, 230, and $150^{\circ} \mathrm{C}$, respectively. The initial oven temperature was held at $50^{\circ} \mathrm{C}$ for $2 \mathrm{~min}$ and programmed to increase at $20^{\circ} \mathrm{C} / \mathrm{min}$ to $325^{\circ} \mathrm{C}$ and held for another $11 \mathrm{~min}$, before cycling back to the initial conditions. Peaks were quantified by area integration using a key selected ion (characteristic $\mathrm{m} / \mathrm{z}$ fragment) rather than the total ion chromatogram to minimize integrating coeluting metabolites, and the relative concentrations were determined based on the quantity of the internal standard.

\section{Subcellular localization of ALD1.}

For localization studies in transgenic Arabidopsis thalianal pBAV150::ALD1, homozygous seedlings were sprayed with $30 \mu \mathrm{M}$ dex plus $0.1 \%$ Tween 20 solution and analyzed by confocal microscopy $21 \mathrm{~h}$ later. A Zeiss LSM710 laserscanning confocal microscope (Zeiss, Germany) was used to visualize GFP fluorescence (excitation: $488 \mathrm{~nm}$; emission: 505 to $530 \mathrm{~nm}$ ) and chlorophyll autofluorescence (excitation: 633, emission: 650 to $750 \mathrm{~nm}$ ). Images were taken using an LD C-Apochromat $40 \times / 1.1 \mathrm{~W}$ Korr objective. Images for GFP and plant autofluorescence were acquired for the same field using a sequential acquisition mode. 


\section{Chloroplastic fractionation.}

Chloroplasts were isolated from $1 \mathrm{~g}$ of A. thaliana/pBAV150:: $A L D 1$ seedlings sprayed with $30 \mu \mathrm{M}$ dex plus $0.1 \%$ Tween 20 solution and fractionated $21 \mathrm{~h}$ later. Intact chloroplasts were purified using Percoll gradients as described (Pattanayak et al. 2012). Organelle purity was assessed by Western blot using organelle-specific marker antibodies (see Western blot analysis).

\section{Isolation of proteins for Western blot analysis.}

For immunoblot studies of GFP, cytHsc70, and chloroplast ATPase $\beta$, total (extract before fractionation) and chloroplastic fractions were mixed with sodium dodecyl sulfate (SDS) sample buffer. For analysis of FLS1 and BAK1, leaves (1 g) of 24- to 26day-old plants were excised and collected. Total extracts were isolated in extraction buffer (Chinchilla et al. 2007): $50 \mathrm{mM}$ Tris-HCL (pH8.0), 10\% glycerol, $0.5 \%$ sodium deoxycholate, $1 \%$ Igepal CA-630 from SIGMA, and complete protease inhibitor cocktail from Roche. Cellular debris was removed by centrifugation, and supernatant was mixed with SDS sample buffer.

\section{Western blot analysis.}

Equal amounts of solubilized total proteins were separated by SDS polyacrylamide gel electrophoresis. Primary antibodies used for Western blots were as follows: FLS2 antibody (Chinchilla et al. 2007) (1:500), BAK1 antibody (Agrisera AS12 1858, 1:3,000), GFP antibody (Covance MMS-118P, monoclonal, 1:3000), cytosolic Hsc70 antibody (cytHsc70, Stressgen SPA817, monoclonal, 1:3,000), and ATPase $\beta$ antibody (Drapier et al. 1992) (1:3000). Secondary horseradish peroxidase conjugated antimouse and antirabbit antibodies (Thermo Scientific) were used at 1:1000. SuperSignal West Pico/Femto Stable Peroxidase (Thermo Scientific) was used to detect the signals. GelPro analyzer software was used to quantify bands and Coomassie blue on Western blots by densitometry.

\section{Callose quantitation.}

Callose deposits were stained with aniline blue as described by Kim and Mackey (2008), except that chlorophyll was cleared with ethanol. Leaves from at least six independent plants for each genotype/treatment were used for measurements. Callose was quantified by counting deposits in images taken with an epifluorescence microscope (Zeiss Axioskop, DAPI filter set) using ImageJ software. Data are presented as number of deposits per $1.5 \mathrm{~mm}^{2}$. To induce callose, water or $1 \mu \mathrm{M}$ flg22 was infiltrated into Arabidopsis leaves 16 to $18 \mathrm{~h}$ before fixing in ethanol.

\section{ROS accumulation measurement.}

Leaf discs from 25- to 28-day-old plants were floated on water for $6 \mathrm{~h}$ in 96-well plates. Twelve discs from at least six independent plants for each genotype/treatment were used for measurements. To detect ROS, $0.1 \mu \mathrm{M}$ flg22 and luminol solution (luminol at $34 \mu \mathrm{g} / \mathrm{ml}$ and peroxidase at $20 \mu \mathrm{g} / \mathrm{ml}$ ) was added to the leaf discs, and a microplate reader (Tecan Safire2; Tecan) was used to measure luminescence during $50 \mathrm{~min}$, as described (Schwessinger et al. 2011).

\section{ACKNOWLEDGMENTS}

This research was supported by NSF grant IOS 0957963 to J. T. Greenberg. H. W. Jung was supported by Wu Jang-Choon Project from the Rural Development Administration (RDA) (PJ00785005) and Basic Science Research Program from the National Research Foundation of Korea (20100006441). This research was also supported, in part, by the Genomic Science Program (Science Focus Area Plant:Microbe Interfaces), U.S. Department of Energy, Office of Science, Biological and Environmental Research under the contract DE-AC05-00OR22725.

\section{LITERATURE CITED}

Adio, A. M., Casteel, C. L., De Vos, M., Kim, J. H., Joshi, V., Li, B., Juéry, C., Daron, J., Kliebenstein, D. J., and Jander, G. 2011. Biosynthesis and defensive function of N $\delta$-acetylornithine, a jasmonate-induced Arabidopsis metabolite. Plant Cell 23:3303-3318.

Beckers, G. J. M., Jaskiewicz, M., Liu, Y., Underwood, W. R., He, S. Y., Zhang, S., and Conrath, U. 2009. Mitogen-activated protein kinases 3 and 6 are required for full priming of stress responses in Arabidopsis thaliana. Plant Cell 21:944-953.

Boller, T., and Felix, G. 2009. A renaissance of elicitors: perception of microbe-associated molecular patterns and danger signals by patternrecognition receptors. Annu. Rev. Plant Biol. 60:379-406.

Bryan, J. K.1990. Advances in the biochemistry of amino acid biosynthesis. Pages 403-452 in: The Biochemistry of Plants. J. Mifli, ed. Academic Press, New York.

Cao, H., Bowling, S. A., Gordon, A. S., and Dong, X. 1994. Characterization of an Arabidopsis mutant that is nonresponsive to inducers of systemic acquired resistance. Plant Cell 6:1583-1592.

Cecchini, N. M., Monteoliva, M. I., and Alvarez, M. E. 2011. Proline dehydrogenase contributes to pathogen defense in Arabidopsis. Plant Physiol. 155:1947-1959.

Chaturvedi, R., Venables, B., Petros, R. A., Nalam, V., Li, M., Wang, X., Takemoto, L. J., and Shah, J. 2012. An abietane diterpenoid is a potent activator of systemic acquired resistance. Plant J. 71:161-172.

Chen, W., Li, X., Tian, L., Wu, P., Li, M., Jiang, H., Chen, Y., and Wu, G. 2014. Knockdown of LjALD1, AGD2-like defense response protein 1, influences plant growth and nodulation in Lotus japonicus. J. Integr. Plant Biol. 56:1034-1041.

Chinchilla, D., Zipfel, C., Robatzek, S., Kemmerling, B., Nürnberger, T., Jones, J. D. G., Felix, G., and Boller, T. 2007. A flagellin-induced complex of the receptor FLS2 and BAK1 initiates plant defence. Nature 448:497-500.

Clough, S. J., and Bent, A. F. 1998. Floral dip: a simplified method for Agrobacterium-mediated transformation of Arabidopsis thaliana. Plant J. 16:735-743.

Conrath, U. 2011. Molecular aspects of defence priming. Trends Plant Sci. 16:524-531.

Conrath, U., Beckers, G. J. M., Flors, V., García-Agustín, P., Jakab, G., Mauch, F., Newman, M. A., Pieterse, C. M. J., Poinssot, B., Pozo, M. J., Pugin, A., Schaffrath, U., Ton, J., Wendehenne, D., Zimmerli, L., and Mauch-Mani, B.; Prime-A-Plant Group. 2006. Priming: getting ready for battle. Mol. Plant-Microbe Interact. 19:1062-1071.

Dangl, J. L., and Jones, J. D. 2001. Plant pathogens and integrated defence responses to infection. Nature 411:826-833.

Delaney, T. P., Uknes, S., Vernooij, B., Friedrich, L., Weymann, K., Negrotto, D., Gaffney, T., Gut-Rella, M., Kessmann, H., Ward, E., and Ryals, J. 1994. A central role of salicylic acid in plant disease resistance. Science 266:1247-1250.

Drapier, D., Girard-Bascou, J., and Wollman, F. A. 1992. Evidence for nuclear control of the expression of the atpA and atpB chloroplast genes in Chlamydomonas. Plant Cell 4:283-295.

Emanuelsson, O., Brunak, S., von Heijne, G., and Nielsen, H. 2007. Locating proteins in the cell using TargetP, SignalP and related tools. Nat. Protoc. 2:953-971.

Feys, B. J., Moisan, L. J., Newman, M.-A., and Parker, J. E. 2001. Direct interaction between the Arabidopsis disease resistance signaling proteins, EDS1 and PAD4. EMBO (Eur. Mol. Biol. Organ.) J. 20:5400-5411.

Fragnière, C., Serrano, M., Abou-Mansour, E., Métraux, J.-P., and L'Haridon, F. 2011. Salicylic acid and its location in response to biotic and abiotic stress. FEBS (Fed. Eur. Biochem. Soc.) Lett. 585:1847-1852.

Glazebrook, J., Rogers, E. E., and Ausubel, F. M. 1996. Isolation of Arabidopsis mutants with enhanced disease susceptibility by direct screening. Genetics 143:973-982.

Glazebrook, J., Zook, M., Mert, F., Kagan, I., Rogers, E. E., Crute, I. R., Holub, E. B., Hammerschmidt, R., and Ausubel, F. M. 1997. Phytoalexin-deficient mutants of Arabidopsis reveal that PAD4 encodes a regulatory factor and that four PAD genes contribute to downy mildew resistance. Genetics 146:381-392.

Glazebrook, J., Chen, W., Estes, B., Chang, H.-S., Nawrath, C., Métraux, J.-P., Zhu, T., and Katagiri, F. 2003. Topology of the network integrating salicylate and jasmonate signal transduction derived from global expression phenotyping. Plant J. 34:217-228.

Gómez-Gómez, L., and Boller, T. 2000. FLS2: an LRR receptor-like kinase involved in the perception of the bacterial elicitor flagellin in Arabidopsis. Mol. Cell 5:1003-1011.

Gómez-Gómez, L., Felix, G., and Boller, T. 1999. A single locus determines sensitivity to bacterial flagellin in Arabidopsis thaliana. Plant J. 18:277-284. 
Greenberg, J. T., Silverman, F. P., and Liang, H. 2000. Uncoupling salicylic acid-dependent cell death and defense-related responses from disease resistance in the Arabidopsis mutant acd5. Genetics 156:341-350.

Gupta, V., Willits, M. G., and Glazebrook, J. 2000. Arabidopsis thaliana EDS4 contributes to salicylic acid (SA)-dependent expression of defense responses: evidence for inhibition of jasmonic acid signaling by SA Mol. Plant-Microbe Interact. 13:503-511.

Guttman, D. S., and Greenberg, J. T. 2001. Functional analysis of the type III effectors AvrRpt 2 and AvrRpm1 of Pseudomonas syringae with the use of a single-copy genomic integration system. Mol. Plant-Microbe Interact. 14:145-155.

Heese, A., Hann, D. R., Gimenez-Ibanez, S., Jones, A. M. E., He, K., Li, J., Schroeder, J. I., Peck, S. C., and Rathjen, J. P. 2007. The receptor-like kinase SERK3/BAK1 is a central regulator of innate immunity in plants. Proc. Natl. Acad. Sci. U.S.A. 104:12217-12222.

Jirage, D., Tootle, T. L., Reuber, T. L., Frost, L. N., Feys, B. J., Parker, J. E., Ausubel, F. M., and Glazebrook, J. 1999. Arabidopsis thaliana PAD4 encodes a lipase-like gene that is important for salicylic acid signaling Proc. Natl. Acad. Sci. U.S.A. 96:13583-13588.

Jones, J. D. G., and Dangl, J. L. 2006. The plant immune system. Nature 444:323-329.

Jung, H. W., Tschaplinski, T. J., Wang, L., Glazebrook, J., and Greenberg, J. T. 2009. Priming in systemic plant immunity. Science 324: 89-91.

Kadota, Y., Sklenar, J., Derbyshire, P., Stransfeld, L., Asai, S., Ntoukakis, V., Jones, J. D., Shirasu, K., Menke, F., Jones, A., and Zipfel, C. 2014. Direct regulation of the NADPH oxidase RBOHD by the PRRassociated kinase BIK1 during plant immunity. Mol. Cell 54:43-55.

Kim, M. G., and Mackey, D. 2008. Measuring cell-wall-based defenses and their effect on bacterial growth in Arabidopsis. Methods Mol. Biol. 415: 443-452.

Kohler, A., Schwindling, S., and Conrath, U. 2002. Benzothiadiazoleinduced priming for potentiated responses to pathogen infection, wounding, and infiltration of water into leaves requires the NPR1/ NIM1 gene in Arabidopsis. Plant Physiol. 128:1046-1056.

Lee, M. W., Lu, H., Jung, H. W., and Greenberg, J. T. 2007. A key role for the Arabidopsis WIN3 protein in disease resistance triggered by Pseudomonas syringae that secrete AvrRpt2. Mol. Plant-Microbe Interact. 20:1192-1200.

Lee, J., Teitzel, G. M., Munkvold, K., del Pozo, O., Martin, G. B., Michelmore, R. W., and Greenberg, J. T. 2012. Type III secretion and effectors shape the survival and growth pattern of Pseudomonas syringae on leaf surfaces. Plant Physiol. 158:1803-1818.

Lerich, A., Hillmer, S., Langhans, M., Scheuring, D., van Bentum, P., and Robinson, D. G. 2012. ER import sites and their relationship to ER exit sites: A new model for bidirectional ER-Golgi transport in higher plants. Front. Plant Sci. 3 Article 143

Li, L., Li, M., Yu, L., Zhou, Z., Liang, X., Liu, Z., Cai, G., Gao, L., Zhang, X., Wang, Y., Chen, S., and Zhou, J.-M. 2014. The FLS2-associated kinase BIK1 directly phosphorylates the NADPH oxidase RbohD to control plant immunity. Cell Host Microbe 15:329-338.

Liu, Y., Schiff, M., Marathe, R., and Dinesh-Kumar, S. P. 2002. Tobacco Rar1, EDS1 and NPR1/NIM1 like genes are required for N-mediated resistance to Tobacco mosaic virus. Plant J. 30:415-429.

Liu, G., Ji, Y., Bhuiyan, N. H., Pilot, G., Selvaraj, G., Zou, J., and Wei, Y. 2010. Amino acid homeostasis modulates salicylic acid-associated redox status and defense responses in Arabidopsis. Plant Cell 22:3845-3863.

Ljung, K., Hull, A. K., Kowalczyk, M., Marchant, A., Celenza, J., Cohen, J. D., and Sandberg, G. 2002. Biosynthesis, conjugation, catabolism and homeostasis of indole-3-acetic acid in Arabidopsis thaliana. Plant Mol. Biol. 49:249-272.

Lu, H., Rate, D. N., Song, J. T., and Greenberg, J. T. 2003. ACD6, a novel ankyrin protein, is a regulator and an effector of salicylic acid signaling in the Arabidopsis defense response. Plant Cell 15: 2408-2420.

Lu, H., Salimian, S., Gamelin, E., Wang, G., Fedorowski, J., LaCourse, W., and Greenberg, J. T. 2009. Genetic analysis of acd6-1 reveals complex defense networks and leads to identification of novel defense genes in Arabidopsis. Plant J. 58:401-412.

Macho, A. P., and Zipfel, C. 2014. Plant PRRs and the activation of innate immune signaling. Mol. Cell 54:263-272.

Mauch-Mani, B., and Métraux, J.-P. 1998. Salicylic acid and systemic acquired resistance to pathogen attack. Ann. Bot. 82:535-540.

Mishina, T. E., and Zeier, J. 2006. The Arabidopsis flavin-dependent monooxygenase FMO1 is an essential component of biologically induced systemic acquired resistance. Plant Physiol. 141:1666-1675.

Mishina, T. E., and Zeier, J. 2007. Pathogen-associated molecular pattern recognition rather than development of tissue necrosis contributes to bacterial induction of systemic acquired resistance in Arabidopsis. Plant J. 50:500-513.

Namwat, W., Kinoshita, H., and Nihira, T. 2002. Identification by heterologous expression and gene disruption of VisA as L-lysine 2-aminotransferase essential for virginiamycin $\mathrm{S}$ biosynthesis in Streptomyces virginiae. J. Bacteriol. 184:4811-4818.

Návarová, H., Bernsdorff, F., Döring, A.-C., and Zeier, J. 2012. Pipecolic acid, an endogenous mediator of defense amplification and priming, is a critical regulator of inducible plant immunity. Plant Cell 24:5123-5141.

Nawrath, C., and Métraux, J. P. 1999. Salicylic acid induction-deficient mutants of Arabidopsis express PR-2 and PR-5 and accumulate high levels of camalexin after pathogen inoculation. Plant Cell 11:1393-1404

Nawrath, C., Heck, S., Parinthawong, N., and Métraux, J. P. 2002. EDS5, an essential component of salicylic acid-dependent signaling for disease resistance in Arabidopsis, is a member of the MATE transporter family. Plant Cell 14:275-286.

Okrent, R. A., and Wildermuth, M. C. 2011. Evolutionary history of the GH3 family of acyl adenylases in rosids. Plant Mol. Biol. 76:489-505.

Padmanabhan, M. S., and Dinesh-Kumar, S. P. 2010. All hands on deck-the role of chloroplasts, endoplasmic reticulum, and the nucleus in driving plant innate immunity. Mol. Plant-Microbe Interact. 23 1368-1380.

Pattanayak, G. K., Venkataramani, S., Hortensteiner, S., Kunz, L., Christ, B., Moulin, M., Smith, A. G., Okamoto, Y., Tamiaki, H., Sugishima, M. and Greenberg, J. T. 2012. Accelerated cell death 2 suppresses mitochondrial oxidative bursts and modulates cell death in Arabidopsis. Plant J. 69:589-600.

Piotrowska, A., and Bajguz, A. 2011. Conjugates of abscisic acid, brassinosteroids, ethylene, gibberellins, and jasmonates. Phytochemistry 72:2097-2112.

Rietz, S., Stamm, A., Malonek, S., Wagner, S., Becker, D., MedinaEscobar, N., Vlot, A. C., Feys, B. J., Niefind, K., and Parker, J. E. 2011 Different roles of enhanced disease susceptibility 1 (EDS1) bound to and dissociated from phytoalexin deficient4 (PAD4) in Arabidopsis immunity. New Phytol. 191:107-119.

Robert-Seilaniantz, A., Navarro, L., Bari, R., and Jones, J. D. G. 2007. Pathological hormone imbalances. Curr. Opin. Plant Biol. 10:372-379.

Ross, A., Yamada, K., Hiruma, K., Yamashita-Yamada, M., Lu, X., Takano, Y., Tsuda, K., and Saijo, Y. 2014. The Arabidopsis PEPR pathway couples local and systemic plant immunity. EMBO (Eur. Mol. Biol. Organ.) J. 33:62-75.

Roux, M., Schwessinger, B., Albrecht, C., Chinchilla, D., Jones, A., Holton, N., Malinovsky, F. G., Tör, M., de Vries, S., and Zipfel, C. 2011. The Arabidopsis leucine-rich repeat receptor-like kinases BAK1/SERK3 and BKK1/SERK4 are required for innate immunity to hemibiotrophic and biotrophic pathogens. Plant Cell 23:2440-2455.

Sato, M., Tsuda, K., Wang, L., Coller, J., Watanabe, Y., Glazebrook, J., and Katagiri, F. 2010. Network modeling reveals prevalent negative regulatory relationships between signaling sectors in Arabidopsis immune signaling. PLoS Pathog. 6:e1001011.

Schwessinger, B., Roux, M., Kadota, Y., Ntoukakis, V., Sklenar, J., Jones, A., and Zipfel, C. 2011. Phosphorylation-dependent differential regulation of plant growth, cell death, and innate immunity by the regulatory receptor-like kinase BAK1. PLoS Genet. 7:e1002046.

Seskar, M., Shulaev, V., and Raskin, I. 1998. Endogenous methyl salicylate in pathogen-inoculated tobacco plants. Plant Physiol. 116:387-392.

Shapiro, A. D., and Zhang, C. 2001. The role of NDR1 in avirulence genedirected signaling and control of programmed cell death in Arabidopsis. Plant Physiol. 127:1089-1101.

Sønderby, I. E., Geu-Flores, F., and Halkier, B. A. 2010. Biosynthesis of glucosinolates-gene discovery and beyond. Trends Plant Sci. 15: 283-290.

Song, J. T., Lu, H., and Greenberg, J. T. 2004a. Divergent roles in Arabidopsis thaliana development and defense of two homologous genes, aberran growth and death2 and AGD2-LIKE DEFENSE RESPONSE PROTEIN1, encoding novel aminotransferases. Plant Cell 16:353-366.

Song, J. T., Lu, H., McDowell, J. M., and Greenberg, J. T. 2004b. A key role for ALD1 in activation of local and systemic defenses in Arabidopsis. Plant J. 40:200-212.

Strawn, M. A., Marr, S. K., Inoue, K., Inada, N., Zubieta, C., and Wildermuth, M. C. 2007. Arabidopsis isochorismate synthase functional inpathogen-induced salicylate biosynthesis exhibits properties consistent with a role in diverse stress responses. J. Biol. Chem. 282:5919-5933.

Stuttmann, J., Hubberten, H.-M., Rietz, S., Kaur, J., Muskett, P., Guerois, R., Bednarek, P., Hoefgen, R., and Parker, J. E. 2011. Perturbation of Arabidopsis amino acid metabolism causes incompatibility with the adapted biotrophic pathogen Hyaloperonospora arabidopsidis. Plant Cell 23:2788-2803 
Taler, D., Galperin, M., Benjamin, I., Cohen, Y., and Kenigsbuch, D. 2004. Plant eR genes that encode photorespiratory enzymes confer resistance against disease. Plant Cell 16:172-184.

Tsuda, K., Sato, M., Glazebrook, J., Cohen, J. D., and Katagiri, F. 2008. Interplay between MAMP-triggered and SA-mediated defense responses. Plant J. 53:763-775.

Tsuda, K., Sato, M., Stoddard, T., Glazebrook, J., and Katagiri, F. 2009. Network properties of robust immunity in plants. PLoS Genet. 5:e1000772.

van Damme, M., Zeilmaker, T., Elberse, J., Andel, A., de Sain-van der Velden, M., and van den Ackerveken, G. 2009. Downy mildew resistance in Arabidopsis by mutation of HOMOSERINE KINASE. Plant Cell 21: 2179-2189.

Verberne, M. C., Sansuk, K., Bol, J. F., Linthorst, H. J. M., and Verpoorte, R. 2007. Vitamin K1 accumulation in tobacco plants overexpressing bacterial genes involved in the biosynthesis of salicylic acid. J. Biotechnol. 128:72-79.

Vinatzer, B. A., Teitzel, G. M., Lee, M. W., Jelenska, J., Hotton, S., Fairfax, K., Jenrette, J., and Greenberg, J. T. 2006. The type III effector repertoire of Pseudomonas syringae pv. syringae $\mathrm{B} 728 \mathrm{a}$ and its role in survival and disease on host and non-host plants. Mol. Microbiol. 62:26-44.

Vlot, A. C., Dempsey, D. A., and Klessig, D. F. 2009. Salicylic acid, a multifaceted hormone to combat disease. Annu. Rev. Phytopathol. 47: 177-206.

Vogt, T. 2010. Phenylpropanoid biosynthesis. Mol. Plant 3:2-20.

von Saint Paul, V., Zhang, W., Kanawati, B., Geist, B., Faus-Kessler, T., Schmitt-Kopplin, P., and Schäffner, A. R. 2011. The Arabidopsis glucosyltransferase UGT76B1 conjugates isoleucic acid and modulates plant defense and senescence. Plant Cell 23:4124-4145.

Wang, C., El-Shetehy, M., Shine, M. B., Yu, K., Navarre, D., Wendehenne, D., Kachroo, A., and Kachroo, P. 2014. Free radicals mediate systemic acquired resistance. Cell Rep. 7:348-355.
Wildermuth, M. C., Dewdney, J., Wu, G., and Ausubel, F. M. 2001 Isochorismate synthase is required to synthesize salicylic acid for plant defence. Nature 414:562-565.

Yi, S. Y., Shirasu, K., Moon, J. S., Lee, S.-G., and Kwon, S.-Y. 2014. The activated SA and JA signaling pathways have an influence on flg22triggered oxidative burst and callose deposition. PLoS ONE 9: e88951.

Yu, K., Soares, J. M., Mandal, M. K., Wang, C., Chanda, B., Gifford, A. N., Fowler, J. S., Navarre, D., Kachroo, A., and Kachroo, P. 2013. A feedback regulatory loop between G3P and lipid transfer proteins DIR1 and AZI1 mediates azelaic-acid-induced systemic immunity. Cell Rep. 3:1266-1278.

Zhang, Z., Shrestha, J., Tateda, C., and Greenberg, J. T. 2014. Salicylic acid signaling controls the maturation and localization of the Arabidopsis defense protein ACCELERATED CELL DEATH6. Mol. Plant 7: 1365-1383 10.1093/mp/ssu072.

Zhou, N., Tootle, T. L., Tsui, F., Klessig, D. F., and Glazebrook, J. 1998. PAD4 functions upstream from salicylic acid to control defense responses in Arabidopsis. Plant Cell 10:1021-1030.

Zimmerli, L., Jakab, G., Métraux, J. P., and Mauch-Mani, B. 2000 Potentiation of pathogen-specific defense mechanisms in Arabidopsis by beta -aminobutyric acid. Proc. Natl. Acad. Sci. U.S.A. 97: 12920-12925.

Zipfel, C., Robatzek, S., Navarro, L., Oakeley, E. J., Jones, J. D. G., Felix, G., and Boller, T. 2004. Bacterial disease resistance in Arabidopsis through flagellin perception. Nature 428:764-767.

\section{AUTHOR-RECOMMENDED INTERNET RESOURCE}

The Gene Indices: compbio.dfci.harvard.edu/tgi/ 